\title{
Non-linear shear strength for rock, rock joints, rockfill and interfaces
}

\author{
Nick Barton ${ }^{1}$
}

Received: 10 May 2016/Accepted: 12 May 2016/Published online: 17 August 2016

(C) Springer International Publishing Switzerland 2016. This article is published with open access at Springerlink.com

\begin{abstract}
Although intact rock is frequently represented by linear Mohr-Coulomb shear strength envelopes, the actual true behaviour, if taken over a wide range of confining stress, is extremely non-linear. Why is this important? Probably because the real stress across points of contact in both rockfill and rock joints is approaching (or trying to exceed) the crushing strength, and if local confined stresses are equally high, strong non-linearity will be experienced. If we utilize the unconfined compression strength of the rockfill, or of the rock joint surfaces, suitably scaled-down due to size effects, we are part way towards a useful strength criterion. In fact, as we will see, we are "one-third" of the way, as the roughness (of particles and asperities) and a measure of the non-dilatant (residual) frictional strengths are also needed for what we will see are two very closely related strength criteria.
\end{abstract}

Keywords Joints - Rockfill - Interfaces - Shear strength · Asperities · Dilation

Quotation

Terzaghi (1920) quoted by Marsal [18]

The fundamental error was introduced by Coulomb, who purposely ignored the fact that sand consists of individual grains, and who dealt with the sand as if it were a homogeneous mass with certain mechanical properties. Coulomb's idea ... developed into an obstacle against further progress as soon as its hypothetical character came to be forgotten by Coulomb's successors.

Nick Barton

nickrbarton@hotmail.com

1 Nick Barton and Associates, Oslo, Norway
The response in 2016

The 'Coulomb error' is still present in rock mechanics. In fact most rock-related strength envelopes are non-linear, the exception being planar rock joints. Even rough-surfaced rock joints have no cohesion unless with actual steps preventing shearing. If a rock mass has a cohesive component due to intact 'bridges' (or such steps) it is not correct to add the cohesive and frictional components: they are mobilized at successively larger shear strain or displacement. Rock masses are also 'particulate' media, with blocks instead of sand grains or gravel or stones. Use of linear Mohr-Coulomb is a tragic error pervading structural geology, petroleum engineering and a lot of rock mechanics. It gives many misleading results in relation to reality, including an exaggeration of petroleum reservoir production potential in the weaker rock types.

\section{Dedication}

Thirty-five years ago, while preparing a paper summarizing some work on the shear strength of rockfill [13], the writer came across some of the work by the person we are now honouring. With degrees from MIT and Harvard and lectures from Terzaghi and Casagrande, and more importantly a distinguished career in famous institutes in Mexico City, it is very clear that Raul Marsal was a person whose work had a high status in the world of rockfill and embankment dam engineering.

One of his landmark papers was the following: Marsal, R.J. 'Mechanical Properties of Rockfill', Embankment-Dam Engineering, Casagrande Volume, R.C. Hirshfeld and S.J. Poulos, eds., John Wiley 
and Sons, Inc., New York, N.Y., 1973, pp. 109-200. Note the large number of pages: this was a major chapter by Dr. Marsal, honouring Casagrande. I quote from part of his abstract:

The analysis and measurement are described of particle breakage, which is a function of the contact forces and the crushing strength of the particles. The devices developed to investigate the shear strength and stress-strain characteristics of rockfills and the techniques for preparation of specimens are described, as well as the measurement of shear strength of rockfill in the triaxial and plane-strain apparatus (Fig. 1).

\section{Introduction}

Although intact rock is frequently represented by linear Mohr-Coulomb shear strength envelopes, the actual true behaviour, if taken over a wide range of confining stress, is extremely non-linear. Why is this important? Probably because the real stress across points of contact in both rockfill and rock joints is approaching (or trying to exceed) the crushing strength, and if locally confined stresses are equally high, strong non-linearity will be experienced. If we utilize the unconfined compression strength of the rockfill, or of the rock joint surfaces, suitably scaled-down due to size effects, we are part way towards a useful strength criterion. In fact, as we will see, we are 'one-third' of the way, as the roughness (of particles and asperities) and a measure of the non-dilatant (residual) frictional strengths are also needed for what we will see are two very closely related strength criteria.

Figure 2 is a representation of the complete shear strength envelope for intact rock, as suggested by Barton [5] following a wide review of other researchers' highpressure triaxial data for intact rock, in particular the wellknown and numerous studies of Byerlee and Mogi from the 1960s. Both these researchers were concerned with the brittle-ductile transition. The present author suggested a simple 'definition' of the top (horizontal) part of the strength envelopes - in rock mechanics terminology called the 'critical state'. The complete shear strength envelopes of rock, and how much they deviate from linear MohrCoulomb have recently been quantified in a new criterion which may become known as the Singh-Singh criterion [21].

The horizontal part of the shear strength envelopes for a large group of silicate and carbonaceous rocks, suggested the following simple relation:

$\sigma_{1 \max }=3 \sigma_{3 \text { critical }}$.

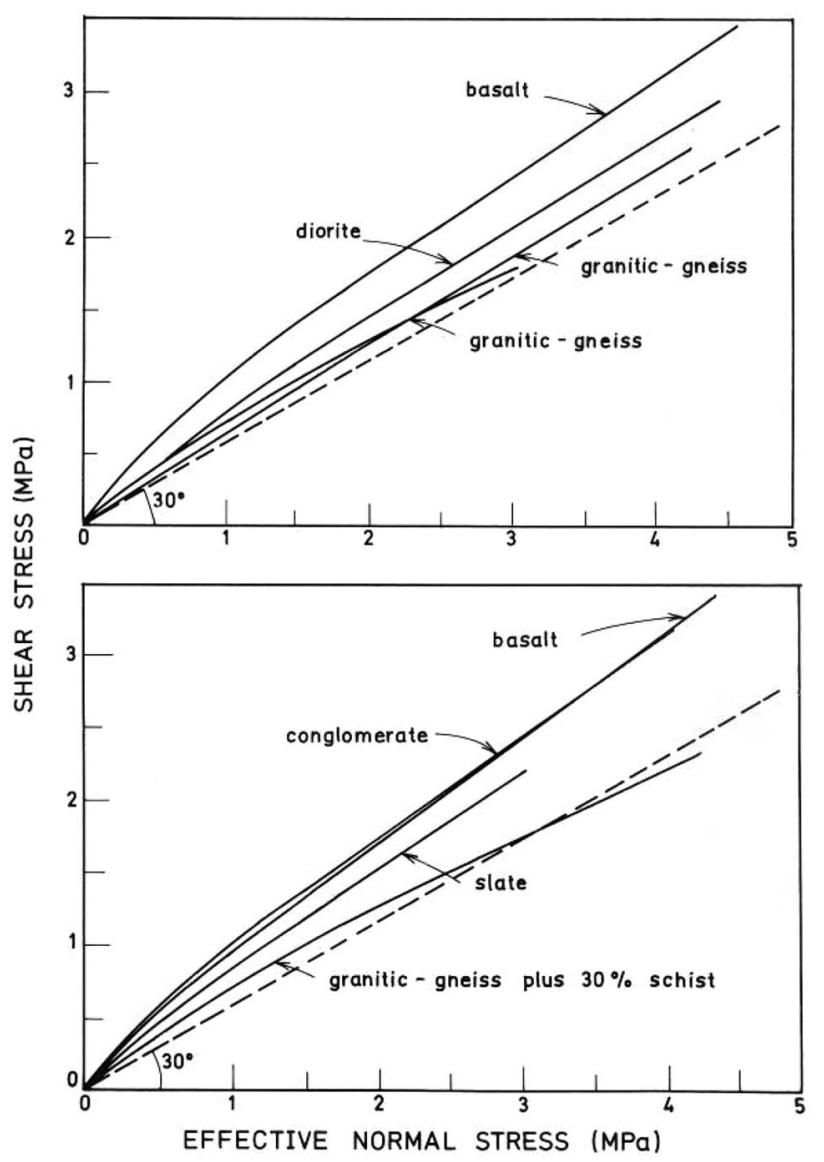

Fig. 1 The significantly non-linear shear strength of various rockfills, as interpreted by Marsal [18]. These simple curves were immediately a source of inspiration to the writer, because they looked just like the shear strength of rock joints [4]. There are several reasons why this is so, and these will be detailed in this paper. It obviously has to do with the highly stressed points of contact in both cases

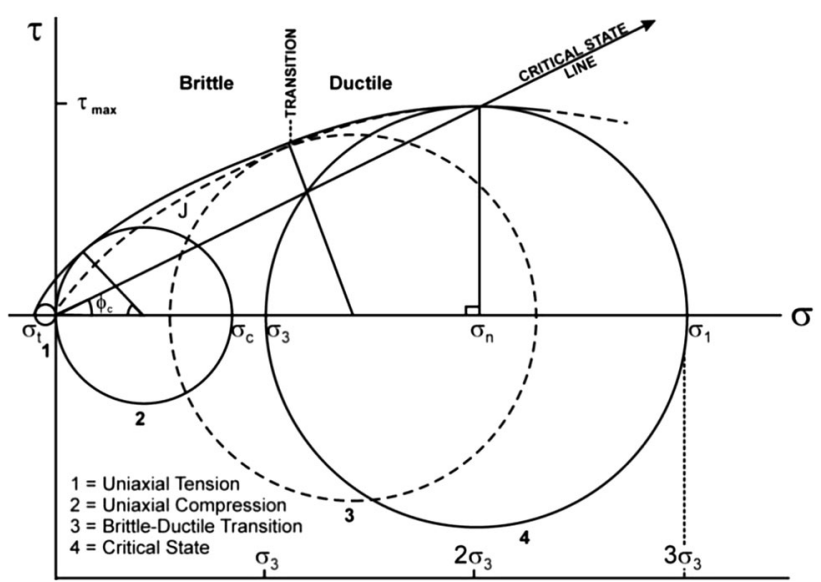

Fig. 2 When tested over a wide range of confining stress, the nonlinearity of the shear strength envelopes for rock is very marked. Note the closeness of Mohr circles \#2 and \#4 [5] 
It will be noted that the uniaxial (unconfined) circle (\#2) and the critical confining pressure circle (\#4) are drawn as nearly tangent to one another. This potential simplicity has recently been confirmed by Singh et al. [21], who found that the majority of rocks exhibited this tendency, i.e. $\sigma_{3 \text { critical }} \approx \sigma_{\mathrm{c}}$. This actually implies that if we reach a confining pressure (over the small area/volume in contact) approximately equal to UCS or $\sigma_{\mathrm{c}}$, a local critical state may potentially be reached if (less confined) crushing has not already occurred. The maximum local rock strength will likely have been exceeded, both for the case of rock joint asperities and the contacting areas/volumes of rockfill particles/stones.

In Fig. 3, we see the near 'super-position' of two envelopes (rock joints and rockfill). It should be noted that the top three envelopes, together with the fifth (lowest) envelope, symbolize the four components of the shear strength of rock masses. For the last 50 years, since the beginning of rock mechanics, this important in situ strength has been assumed to consist of the Mohr-Coulomb $\tau=c+\sigma_{n}^{\prime} \tan \varphi^{\prime}$ (or more recently as the non-linear complex-algebra GSI-based Hoek-Brown criterion). In reality, contrary to the $\mathrm{M}-\mathrm{C}$ or $\mathrm{H}-\mathrm{B}$ assumptions, the shear strength of rock masses consists of the degradation of the cohesion (the intact 'bridges') followed at larger strain by the mobilization of friction and roughness causing dilation. At still greater shear 'strain', any clay-filled discontinuities present may also be mobilized. The failure is, therefore, a progression of components mobilized at different levels of shear 'strain' (or displacement).

\section{From tension fractures to rock joints}

A promising start to an understanding of the shear strength of rough rock surfaces with opposed asperities in contact was experienced by the writer in about 1968, while developing a method to create ' $2 \mathrm{D}$ ' models of variously jointed (fractured) rock masses. Figure 4 (top-left) shows sheardisplaced roughness profiles of brittle tension fractures which have been sheared and dilated exactly as measured in direct shear tests of the same (2D profiled) samples. Very small areas of contact (and, therefore, high contact stresses) are seen as a result of the pre-peak and post-peak shearing. The direct shear tests produced strongly curved peak strength envelopes, especially at very low normal stresses, as shown in the top-right diagram. (Such results were the forerunner of tilt tests developed 10 years later, illustrated in Fig. 5). The two sets of experimental data with results expressed as a function of peak dilation angles (bottom-left) required a small rotation to the dotted lines, to produce the forerunner of the Barton [4] non-linear peak strength criterion. In 1968, 'JRC' was 20 (very rough tension fractures), 'JCS' was UCS (due to no weathering), and $\varphi_{\mathrm{b}}$ was $30^{\circ}$ (also due to no weathering).

The terms JRC (joint roughness coefficient) and JCS (joint-wall compression strength) were first used in Barton [4]. In subsequent experimental work with fresh and partly weathered rock joints (130 samples), acquired from road cuttings in the Oslo area, Barton and Choubey [12] showed that $\varphi_{\mathrm{b}}$ should be replaced by $\varphi_{\mathrm{r}}$ which could be several degrees lower in cases with weathered joint surfaces. The writer developed the tilt test at this time, as a formal way to
Fig. 3 The basic non-linearity of rock, rock fractures, rock joints, and rockfill. Note the deliberate 'super-position' of the strength envelopes for the rock joints and rockfill [11]

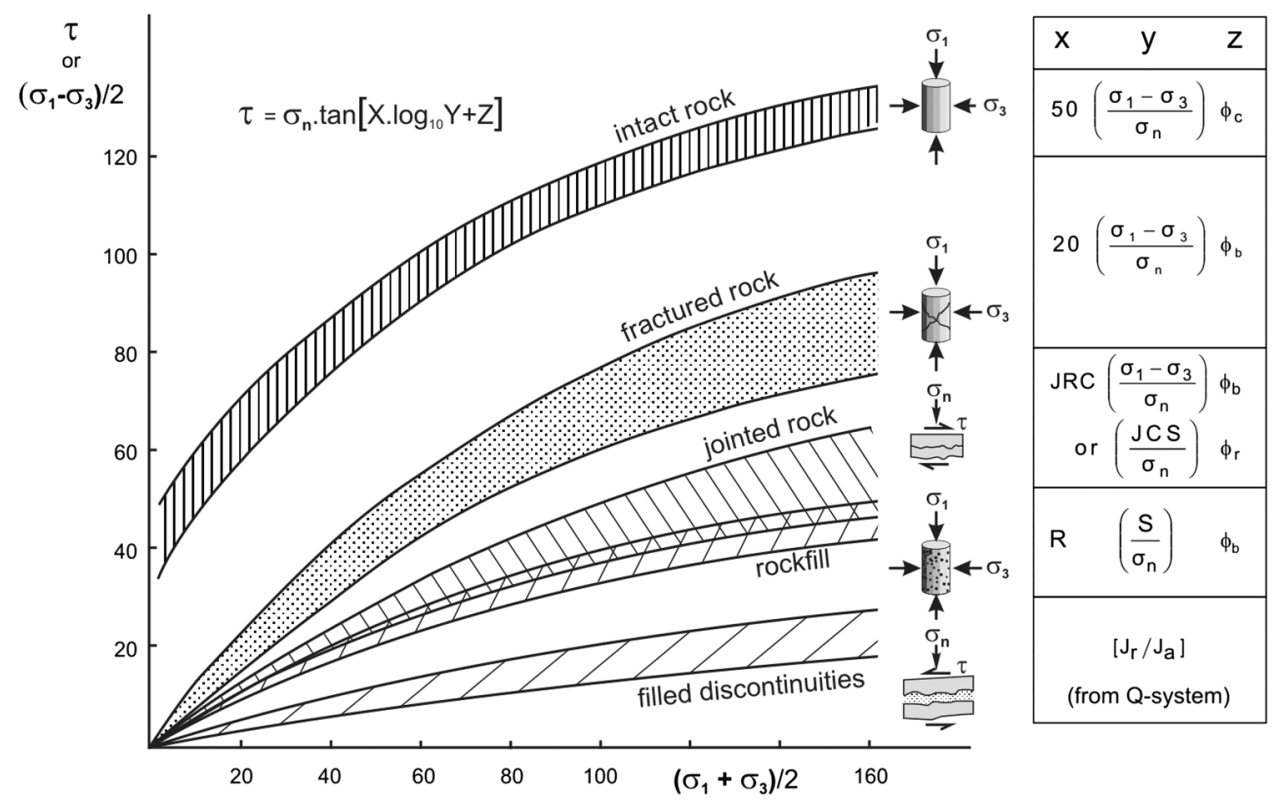




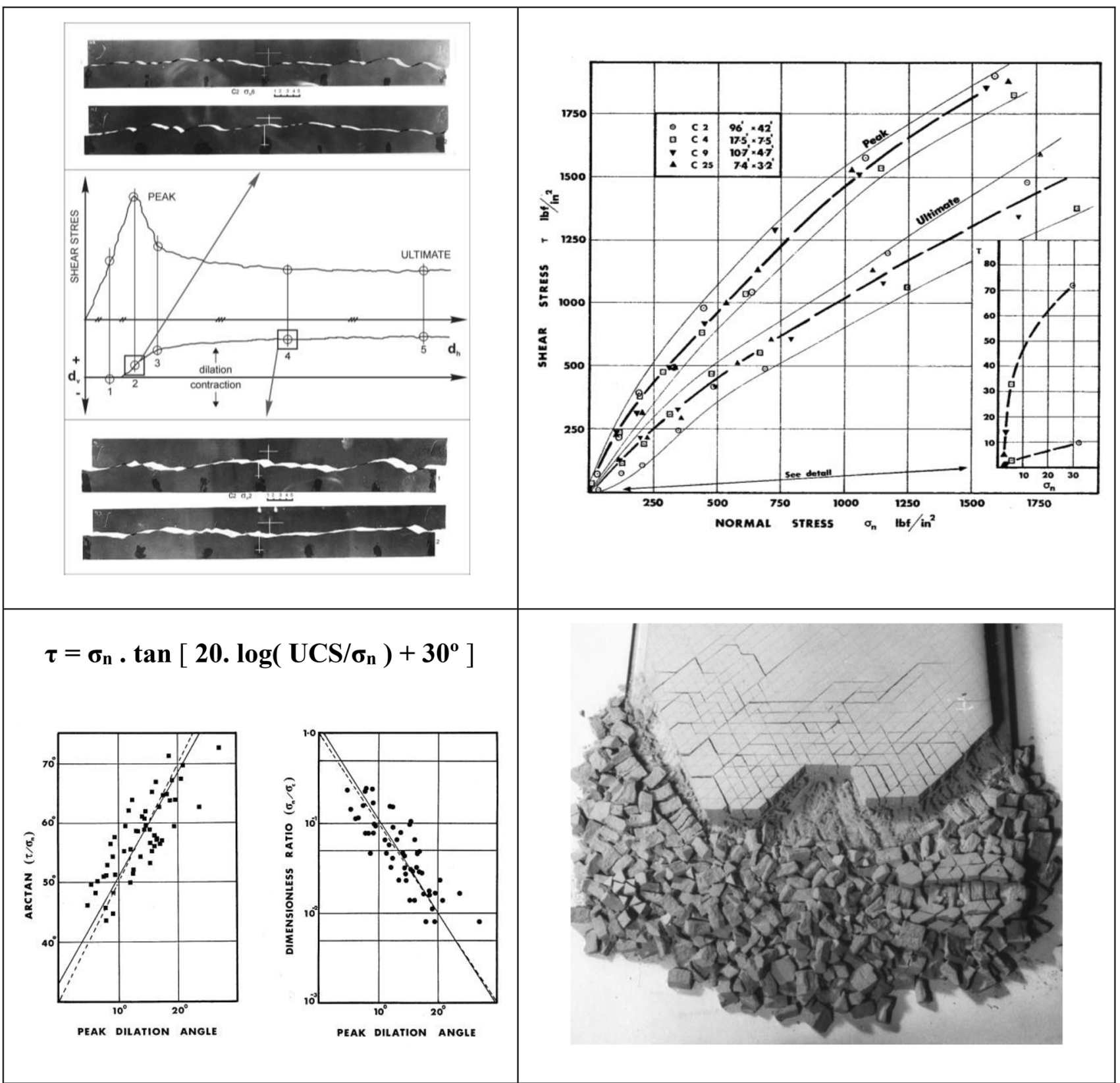

Fig. 4 The origins of the non-linear shear strength criterion for rock joints [4] were the direct shear tests performed on 200 tension fractures in various weak, brittle model materials, which were designed to represent jointed rock masses in $2 \mathrm{D}$, in fact a forerunner

back-calculate the variable joint roughness JRC. Examples of this simple technique are shown in Fig. 5 (Do three tilt tests per sample plus roughness profiling).

Figure 6 shows some of the joint samples tested (with increasing roughness from \#1 to \#10), and two sets of shear strength results. The three shear strength criteria (M-C, Patton, and Barton/Choubey) are compared. By chance the writer's career in rock mechanics started in of the much more flexible UDEC of Cundall, who was a fellow Ph.D. colleague at Imperial College. Note that the prototype (up-scaled) stress levels $\left(\mathrm{lbs} / \mathrm{in}^{2}\right)$ and sample sizes (feet) are given in the top-right diagram

1966, just after the first ISRM congress in Lisbon, where Patton [20] presented his bi-linear equation, which was developed from tests on interlocked 'saw-teeth'. It was an immediate goal to try to improve upon this ' $\varphi+i$ ' criterion, since ' $i$ ' was not sufficiently defined. In due course of time, it was found that ' $i$ ' was both stress and scale dependent. (The term $\mathrm{JRC}_{n} \log _{10} \mathrm{JCS}_{n} / \sigma_{n}$ is required). 
Fig. 5 Tilt tests for backcalculating the joint roughness coefficient JRC. When sliding occurs (usually at tilt angles of $40^{\circ}-80^{\circ}$ ) the gravity loading ensures a uniform shear stress and a uniform normal stress of only about $0.001 \mathrm{MPa}$. The non-linear form of the strength criterion allows this JRC value to be used at three or four orders of magnitude higher normal stress, e.g. 1-10 MPa in rock mechanics design studies. Note the two-core-sticks test for $\varphi_{\mathrm{b}}$ (no polishing, no ridges, use sand-blasting if in doubt). Also shown are a Schmidt hammer and a roughness-profile gauge. The apparatus on the left was used when the writer was at TerraTek (now Schlumberger) and represents one of the simplest rock mechanics tests

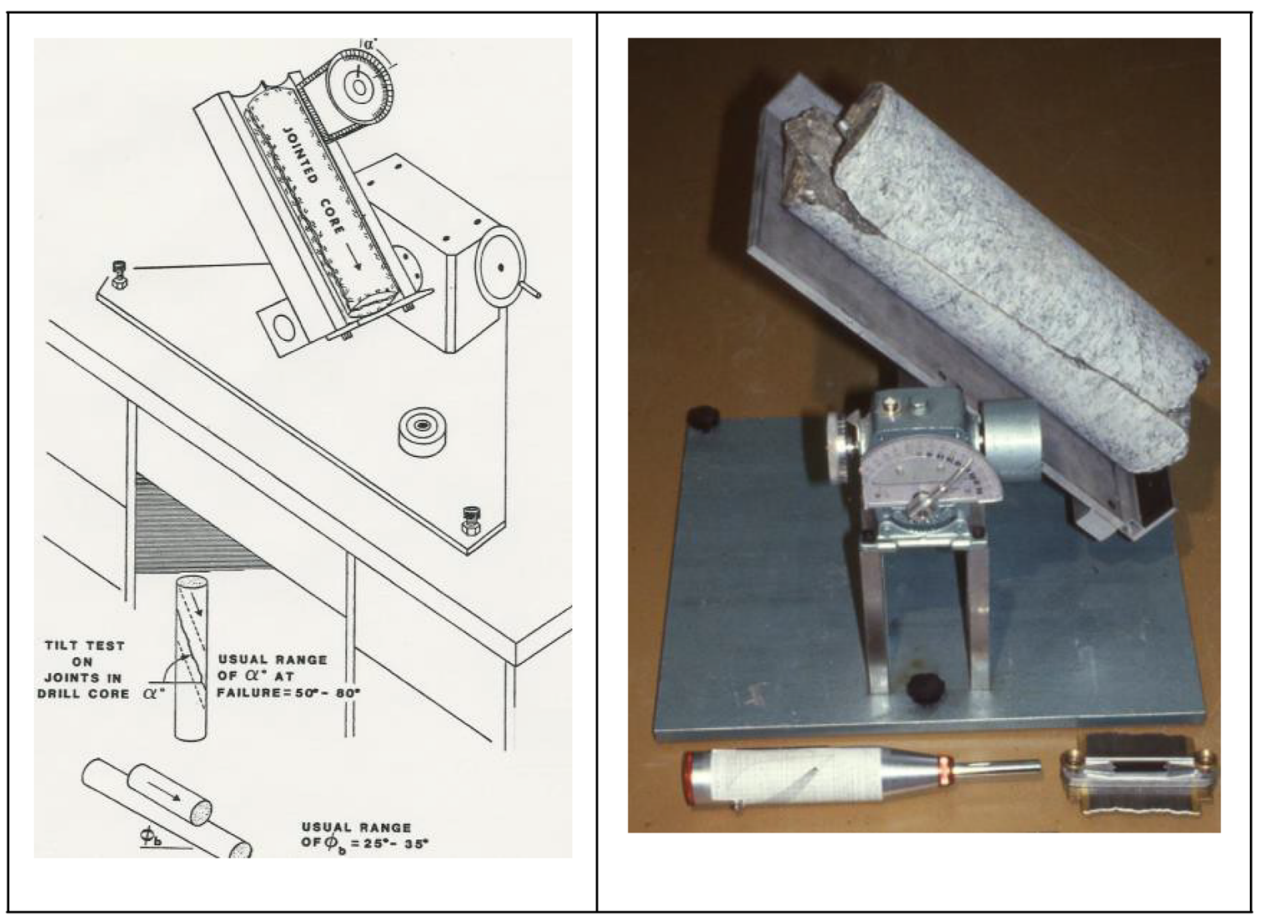

\section{Scale effects for rock joints}

A 'final' stage concerning the writer's non-linear shear strength criterion was the correction of the input parameters JRC and JCS for scale. As we shall see later, a similar scale correction was also necessary for rockfill. The impetus for scale corrections was the result of a milestone series of direct shear tests on joint replicas of different size. By happy coincidence, Bandis started his Ph.D. studies just after the work of Barton and Choubey [12], and made active use of JRC and JCS to record strong scale effects. Figures $7 \mathrm{~b}$ and 8 summarize what Bandis found. As may be noted from Fig. 7a, performing tilt tests on jointed blocks is also a scale-dependent process.

The various stages of development of the shear strength criterion for rock joints, starting with artificial tension fractures, and ending with weathering and scale corrections are listed below. As we shall see, the proposed empirical equation for the shear strength of rock fill and for rockfill/ rock-foundation interfaces have their origin in the highly stressed asperities shown in Fig. 4a.

$$
\begin{aligned}
\tau= & \sigma_{n}^{\prime} \tan \left[20 \log _{10}\left(\mathrm{UCS} / \sigma_{n}^{\prime}\right)+30^{\circ}\right](\text { Barton }[3]) \\
\tau= & \sigma_{n}^{\prime} \tan \left[\mathrm{JRC} \log _{10}\left(\mathrm{JCS} / \sigma_{n}^{\prime}\right)+\varphi_{\mathrm{b}}\right](\text { Barton }[4]) \\
\tau= & \sigma_{n}^{\prime} \tan \left[\mathrm{JRC} \log _{10}\left(\mathrm{JCS} / \sigma_{n}^{\prime}\right)\right. \\
& \left.+\varphi_{\mathrm{r}}\right](\mathrm{Barton} \text { and Choubey }[12]) \\
\tau= & \sigma_{n}^{\prime} \tan \left[\mathrm{JRC}_{n} \log _{10}\left(\mathrm{JCS}_{n} / \sigma_{n}^{\prime}\right)+\varphi_{\mathrm{r}}\right](\text { Bandis et al. [2]) }
\end{aligned}
$$

The collection of simple index tests for obtaining input data for fractures or joints, using tests on core or on samples sawn or drilled from outcrops is shown in Fig. 10. In the left-hand column, direct shear tests are also illustrated, which can be used to verify the results from the empirically developed index tests. Note that the Schmidt hammer should be used on clamped pieces of core to estimate the uniaxial compression strength UCS or $\sigma_{\mathrm{c}}$. This is done on dry pieces of core (rebound $R$, use top $50 \%$ of results). For the joint-wall strength JCS, this is done on saturated samples (rebound $r$, use top $50 \%$ of results). These samples also need to be clamped (e.g. to a heavy metal base). Three methods of joint-wall or fracture-wall roughness (JRC) can be used: tilt tests to measure tilt angle $\alpha$ (i.e. Fig. 5), or $a / L$ (amplitude/ length) measurement, or roughness profile matching; the latter obviously more subjective.

\section{From rock joints to rockfill}

As indicated in the Dedication to this article, the nonlinear shear strength envelopes for rockfills (see Fig. 1) presented by Marsal [18] made a strong impression when these were first seen by the writer in about 1979. Nonlinear strength envelopes were also the dominant theme for rock joints, in the author's work since about 1967: first with artificial tension fractures (in brittle model materials) then with rock joints, with the latter 


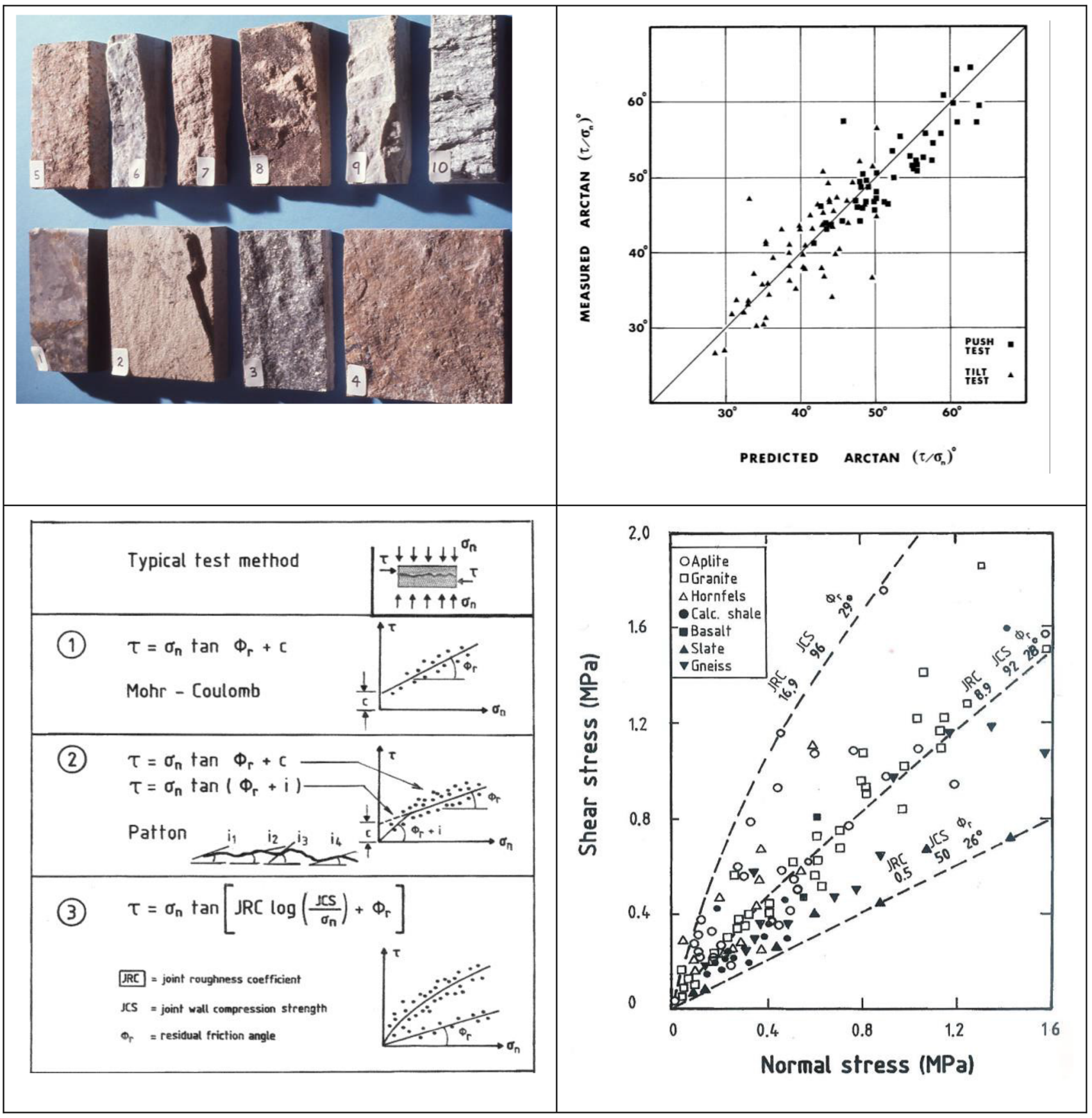

Fig. 6 A brief summary of Barton and Choubey [12]. Examples of the 130 joint samples are shown top-left. (However, sample \#10 was one of six artificial tension fractures). Top-right shows peak friction angles measured in DST compared with the prediction based on gravity-loaded tilt tests and push tests. Good correlation is shown in general, over a wide range of peak shear strengths. The results are also plotted as $\tau$ versus $\sigma_{n}$ (bottom-right), and three strength

contributions starting in Barton [4]. In fact, it is interesting to reproduce one of the early diagrams when JRC and JCS were first suggested, since six of the curved envelopes (Fig. 12) contain within their range, envelopes are drawn (dashed-lines) using maximum strength $(\mathrm{JRC}=16.9)$, mean values of JRC, JCS and $\left.\varphi_{\mathrm{r}}\right)$, and minimum values. The non-linear criterion (\#3) is compared with MohrCoulomb and with Patton [20] (bottom-left). Note that rock joints do not have cohesion unless steep steps are sheared through. But peak total friction angles (including friction, dilation and the asperity strength component) can be very high at low normal stress

something similar to the shear strength of rockfill. It seems that non-linearity was a common but independent pre-occupation in Mexico (for rockfill) and in Norway (for rock joints) in the early 1970s (Fig. 11). 


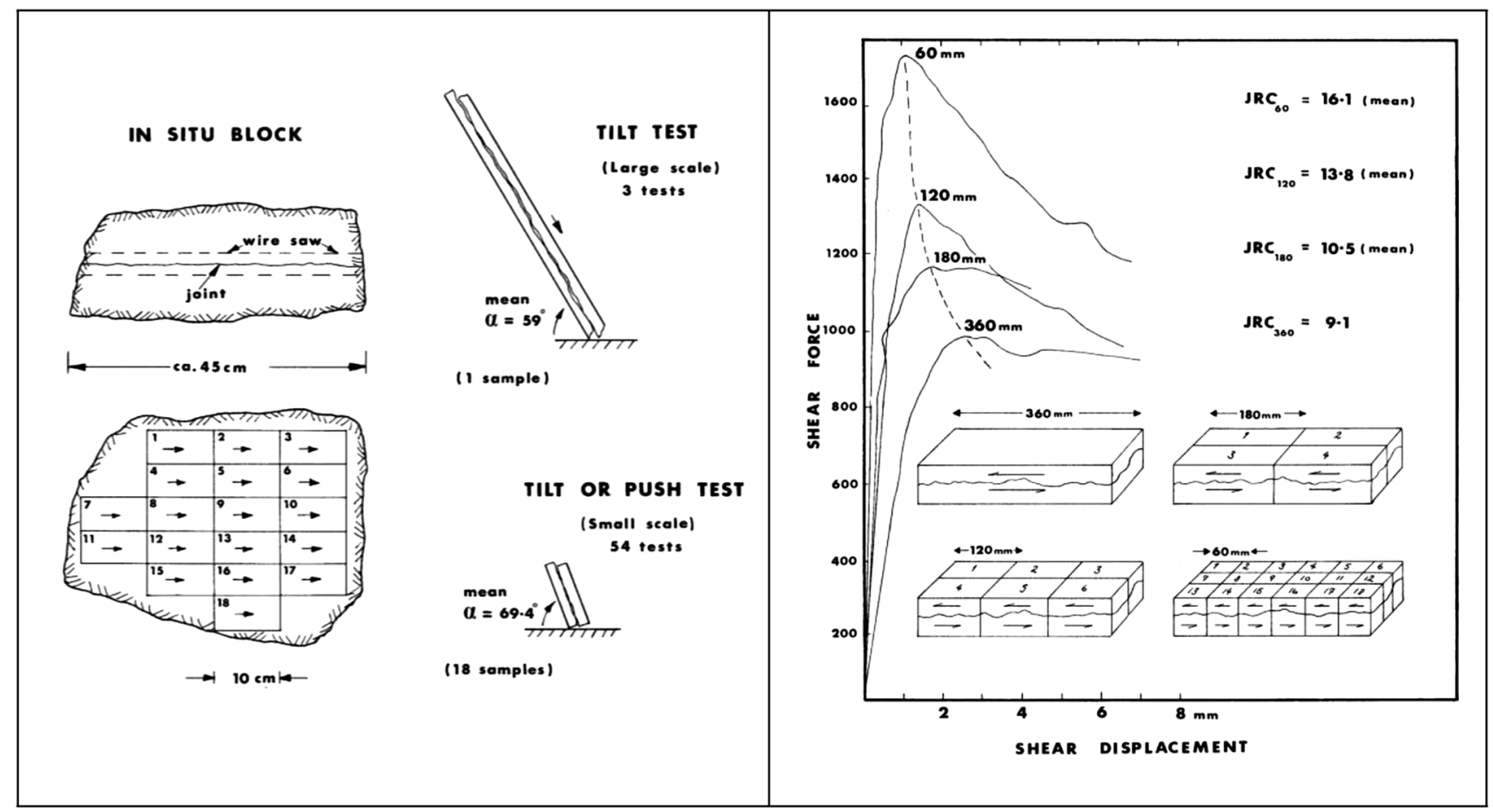

Fig. 7 Left tilt tests performed on a joint in granite by Barton and Choubey [12]. Right direct shear tests of joint replicas by Bandis [1] performed during his Ph.D. studies, published in Bandis et al. [2].
Each of the above indicates that block size-dependent scale corrections are needed for JRC

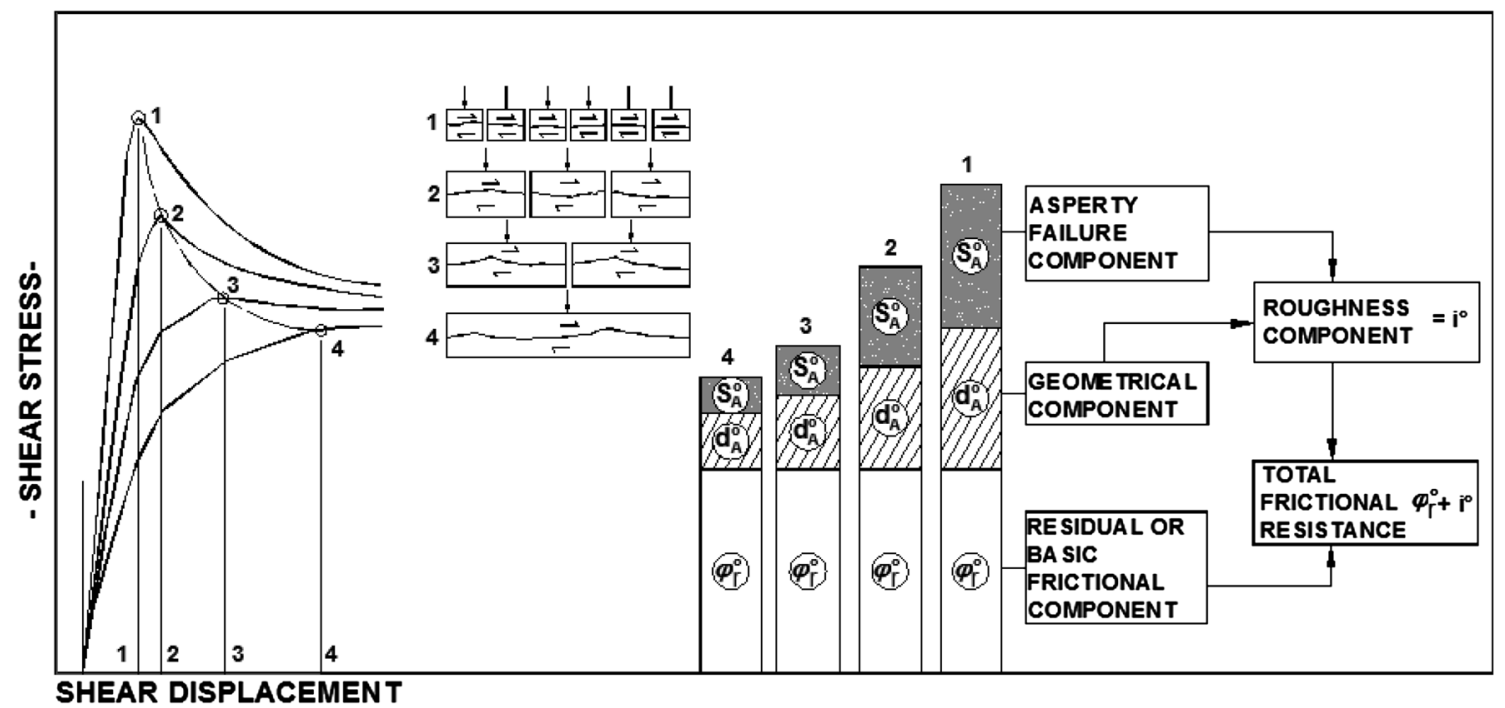

Fig. 8 Two of the key angular components of the shear strength of rock joints $\left(S_{\mathrm{A}}=\right.$ asperity failure component, and $d_{n}=$ peak dilation angle) were shown by Bandis et al. [2] to be scale dependent. The parameters JRC and JCS are involved in both these parameters. This figure illustrates why it is not correct to subtract the dilation angle to obtain a 'basic friction angle', as proposed many times by Hencher, because peak strength includes an asperity strength component. This

Figure 12 shows that there are strong similarities between the shear strength of rockfill and that of rock joints. This is because they both have 'points in contact', error can amount to $10^{\circ}$ as Hencher proposes 'basic friction angles' as high as $40^{\circ}$ for rock slope design, on to which roughness is added. The problem is these so-called 'basic friction angles' are (unintentionally) scale dependent, as clearly shown in this figure from Bandis. Scaling rules for JRC and JCS to obtain $\mathrm{JRC}_{n}$ and $\mathrm{JCS}_{n}$ are shown in Fig. 9. They were published in Bandis et al. [2]

i.e. highly stressed contacting asperities or opposing stones. In fact, these contacting points may be close to their crushing strength, such that similar shear strength 

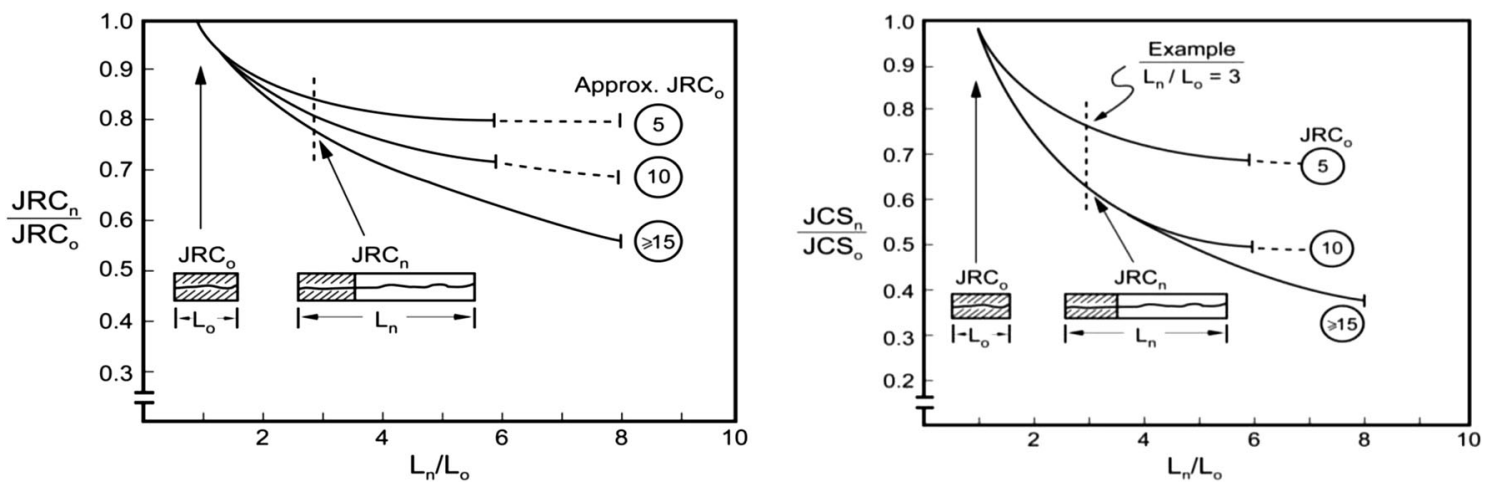

Fig. 9 An empirical-based method to correct JRC and JCS for the effect of block size. Note that $L_{0}$ is the nominal lab-scale value, while $L_{n}$ is the spacing of cross-joints defining the block size in question

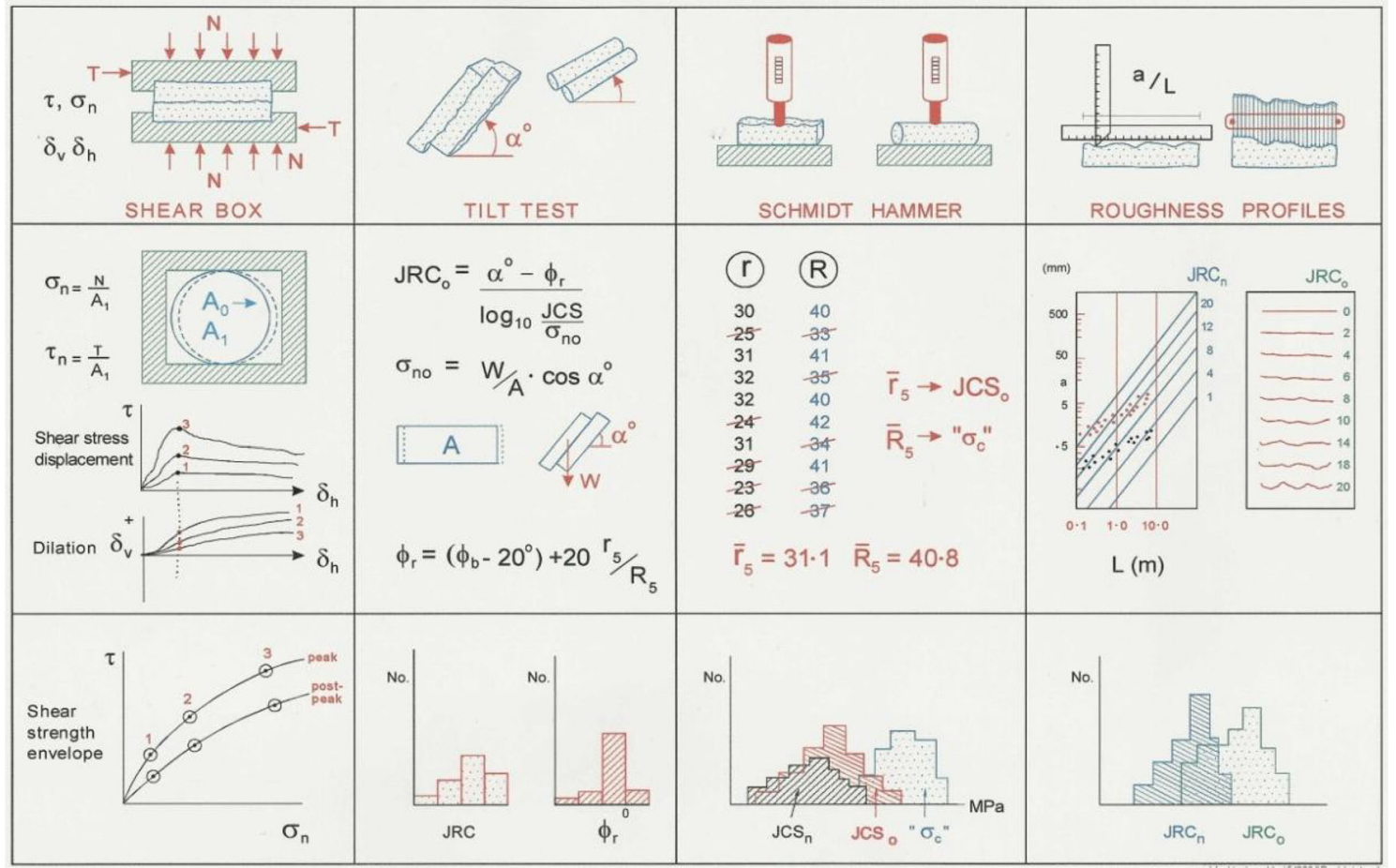

Fig. 10 The index tests required to characterize rock joints, also used to obtain input for shear strength. The tests were introduced by Barton and Choubey [12] and Barton [7] proposed the $a / L$ method for JRC. The present format of tests was presented in Barton [10]
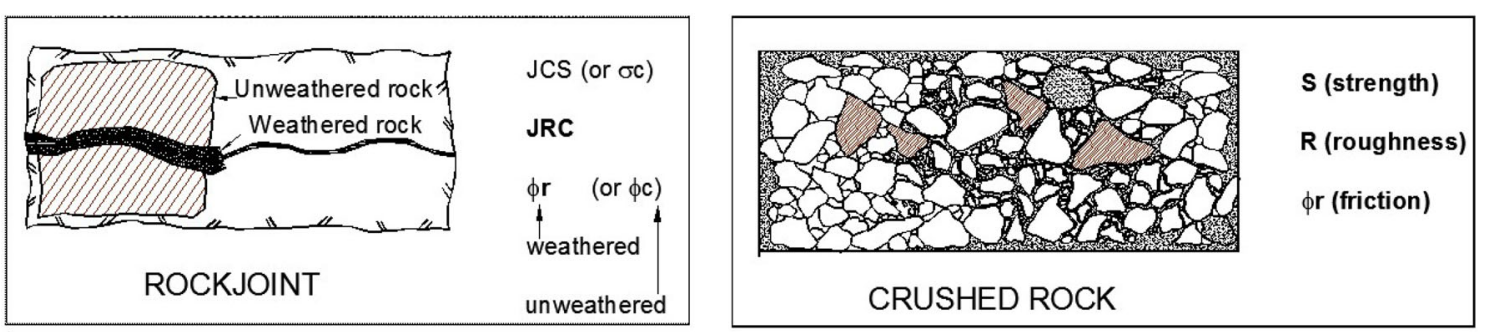

Fig. 11 Empirically derived index properties for rock joints (JRC and JCS) from Barton [4] are the source of the equivalent parameters ( $R$ and $S$ ) for rockfill, used by Barton and Kjærnsli [13] 


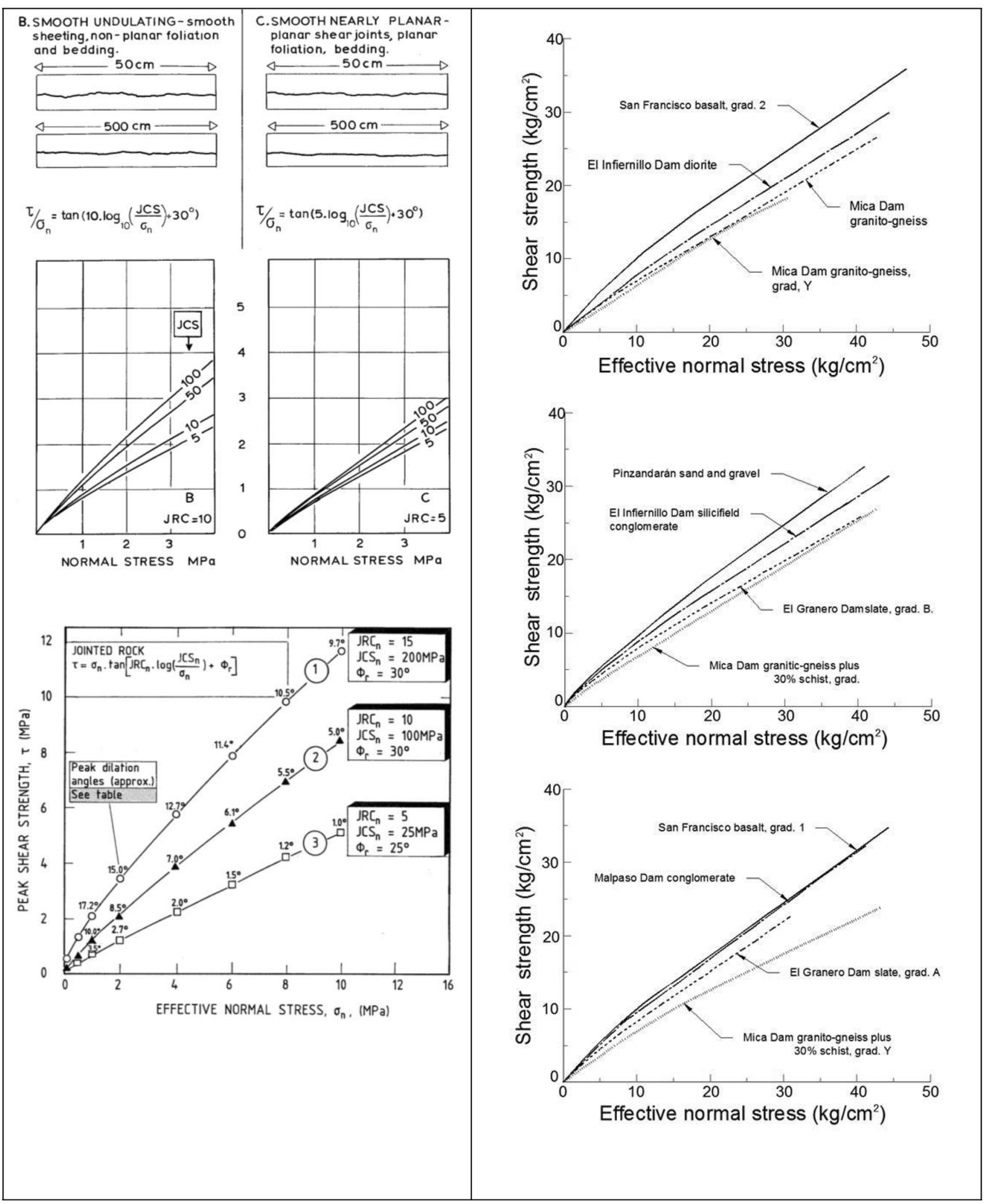

Fig. 12 Top-left part of the suggested method to estimate the peak shear strength envelopes for rock joints of different roughness, from Barton [4]. Bottom-left the addition of estimated peak dilation angles is shown, for three strength envelopes, from Barton [9]. Envelopes \#2 and \#3 also resemble the rockfill strengths: Right the complete set of Mohr envelopes for various granular materials given at the end of the Marsal [18] 'Casagrande' book chapter 


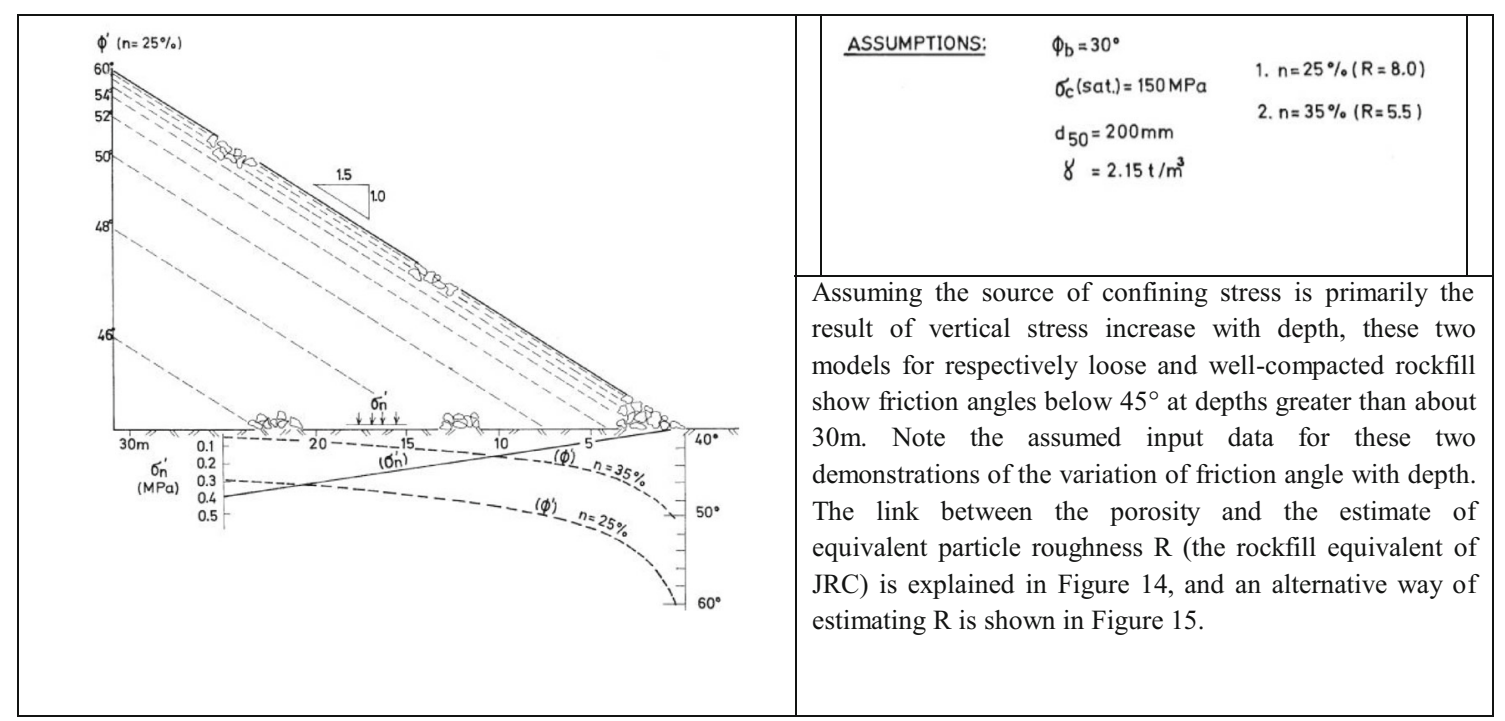

Fig. 13 Two estimates of the stress dependence of friction angles for prospective loose and dense rockfill, using (vertical) depth within a dam slope as a simplified model of confining stress increase

Table 1 The complete set of estimated peak dilation angles, for the three envelopes in Fig. 12 (bottom-left). Note the extremely high values of $d_{n}$ peak predicted when stress levels are low. This resembles rockfill

\begin{tabular}{lrrrrrrrr}
\hline Curve no. & \multicolumn{7}{l}{ Effective normal stress (MPa) } \\
\cline { 2 - 8 } & 0.1 & \multicolumn{1}{c}{0.5} & 1.0 & \multicolumn{1}{c}{2.0} & 4.0 & 6.0 & 8.0 & 10.0 \\
\hline 1 & 24.7 & 19.5 & 17.2 & 15.0 & 12.7 & 11.4 & 10.5 & 9.7 \\
2 & 15.0 & 11.5 & 10.0 & 8.5 & 7.0 & 6.1 & 5.5 & 5.0 \\
3 & 6.0 & 4.2 & 3.5 & 2.7 & 2.0 & 1.5 & 1.2 & 1.0 \\
\hline
\end{tabular}

equations to those used for rock joints can apply to rockfill, and indeed to rockfill/rock interfaces. This can be seen in the progression of equations.

The three equations to be utilized in the remainder of this paper have the shear strength of rock joints as a starting point. The first equation listed was Eq. 4:

1. $\tau / \sigma_{n}=\tan \left[\mathrm{JRC} \cdot \log \left(\mathrm{JCS} / \sigma_{n}\right)+\varphi_{\mathrm{r}}\right] \ldots$ for rock joints

2. $\tau / \sigma_{n}=\tan \left[R \cdot \log \left(S / \sigma_{n}\right)+\varphi_{\mathrm{b}}\right]$.. for rockfill

3. $\tau / \sigma_{n}=\tan \left[\mathrm{JRC} \cdot \log \left(S / \sigma_{n}\right)+\varphi_{\mathrm{r}}\right] \ldots$ for interfaces

(see later).

The equation to be used for a rockfill/rock-foundation interface will depend on whether there is 'JRC' control, or ' $R$ ' control. This distinction: preferential sliding on the interface or shearing within the rockfill is described and illustrated later.

Concerning the potentially very high friction angles at low stress levels, or close to the surface of a rockfill dam embankment (e.g. Fig. 13), Marsal [18] makes mention of a basalt rockfill having $\varphi^{\prime}$ of up to $70^{\circ}$ under a normal effective stress of only $0.1 \mathrm{MPa}$. Although the 'asperity strength' component (Fig. 8) is uncertain for rockfill, if it were of similar magnitude to the peak dilation angle $\left(d_{n}\right.$ peak), as in the case of rock joints, then the latter could be in the region of $20^{\circ}$ at similarly low stress, compatible with the low stress predictions of peak dilation given in Fig. 12 (bottom-left) and in Table 1. Marsal [18] considered that within a rockfill dam, the friction angle of the materials within the range of confining stresses of interest was usually less than the $40^{\circ}-45^{\circ}$ previously assumed, due to the effect of the confining pressure and the non-linearity. This will be explored further.

The non-linearity implied by the rockfill data assembled by Leps [16] shown in the left diagram of Fig. 15 is provided by the linear-phi and log-stress format, which is exactly consistent with the experiences of the shear strength of rock joints shown in the diagram on the right side of Fig. 15. Note the direct 'substitution' of $R$ for JRC and $S$ for JCS, to demonstrate similarity to the data for rockfill. A similar gradient to that drawn by Leps (the middle-of-the-data line) seems to be provided by $R=7.5$ and $S=45 \mathrm{MPa}$.

Large-scale vacuum triaxial cylinders as seen in Fig. 16 have a limit of confinement of $<100 \mathrm{kPa}$. Somewhat smaller but higher pressure triaxial cells, as also used by Marsal [18], and by many others during several decades, were also used in these studies, to reach the higher confining pressures. Of particular note, besides the non-linear stress-dependent friction angles, is the steepness of their decline with increasing stress.

Simple inspection of one order of magnitude stress change, from 0.16 to $1.6 \mathrm{MPa}$, bringing $\varphi^{\prime}$ from $51^{\circ}$ down to almost $39^{\circ}$ suggests an equivalent $R$ value as much as 10.5 , even steeper (rougher) than the highlighted data 


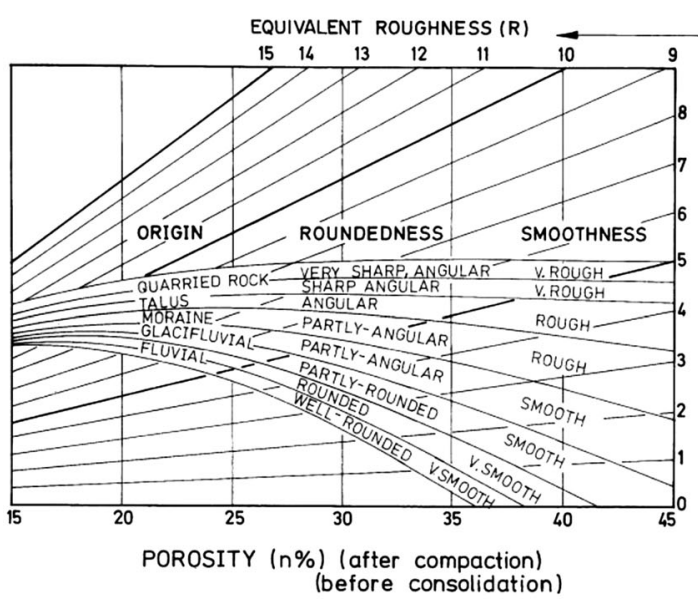

Fig. 14 A simple empirical model from Barton and Kjærnsli [13] for obtaining a preliminary estimate of equivalent roughness $R$ for rockfill materials of different origin, roundedness and porosity. The

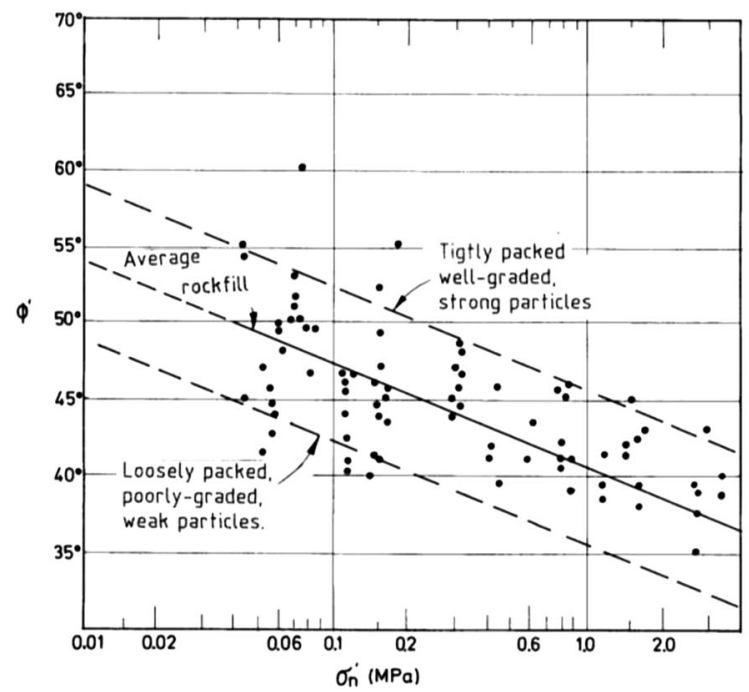

Fig. 15 Left assembly of peak shear strength data for rockfills, from Leps [16]. The logarithmic scale of effective normal stress is further confirmation of the similarity of rockfill and rock joints. Right

shown in Fig. 15. [If smaller particle gradings had been used at the higher stresses, the decline would be much reduced due to higher $S$ values (see Fig. 17)]. Note from Fig. 14 that if quarried rock could be so well graded (thereby filling its voids) and so well compacted that a porosity of $20 \%$ was reached, then an $R$ value as high as 10 can be predicted (close to the ' $Q$ ' of quarried rock in Fig. 14). Beneath $500 \mathrm{~m}$ of cover all is possible.

The necessity to have a scale-effect adjustment for the uniaxial compressive strength of rockfill, following approximately the trend obtained in rock mechanics studies is clear. For simplicity and consistent reference, the

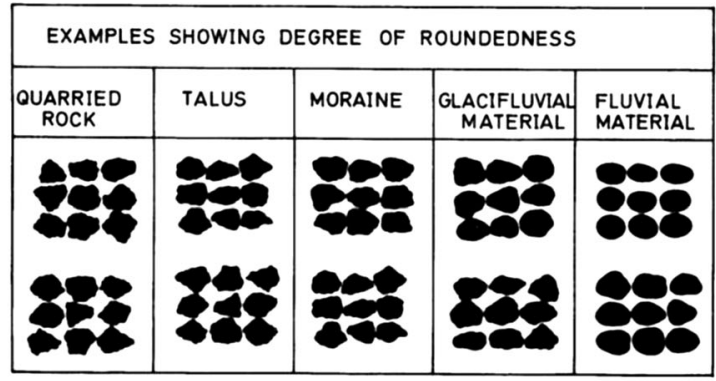

workings of $R$ (and $S$ ) as equivalent rock joint parameters JRC (and JCS) are demonstrated in parallel to the rockfill data assembled by Leps [16], in Fig. 15

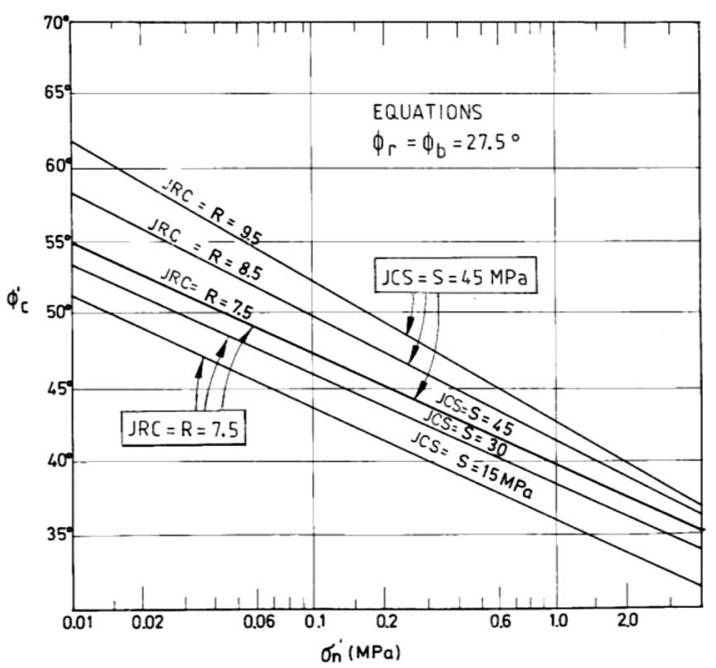

comparative JRC or $R$, and JCS or $S$ values used to generate similar gradients to [16] data for rockfill. $R=5-10$, and $S=10-100 \mathrm{MPa}$ appear to cover the range of strengths assembled by Leps

strength of the $d_{50}$ size is recommended. In the case of the UCS of rock, the following equation suggests itself, based on an averaging of Hoek and Brown and Wagner versions with their slightly diverging exponents of 0.18 and 0.22 : $\sigma_{\mathrm{c}}=\sigma_{\mathrm{c} 50}\left(50 / d_{50}\right)^{0.2}$. The term $\sigma_{\mathrm{c} 50}$ is the standard $(50 \mathrm{~mm}$ diameter) size of UCS specimens. The diameter $d_{50}$ is the stone size. The way that $R$ (or JRC) causes a change of $R^{\circ}$ (or $\mathrm{JRC}^{\circ}$ ) (i.e. change of angular degrees) per decade change of effective stress or equivalent overburden depth is demonstrated in Table 2. It seems logical to assume that 20, and JRC (and $\mathrm{JRC}_{n}$ ) seen earlier in Eqs. 1 through 6 actually have units of degrees, as in the case of Patton's ' $i$ ' 


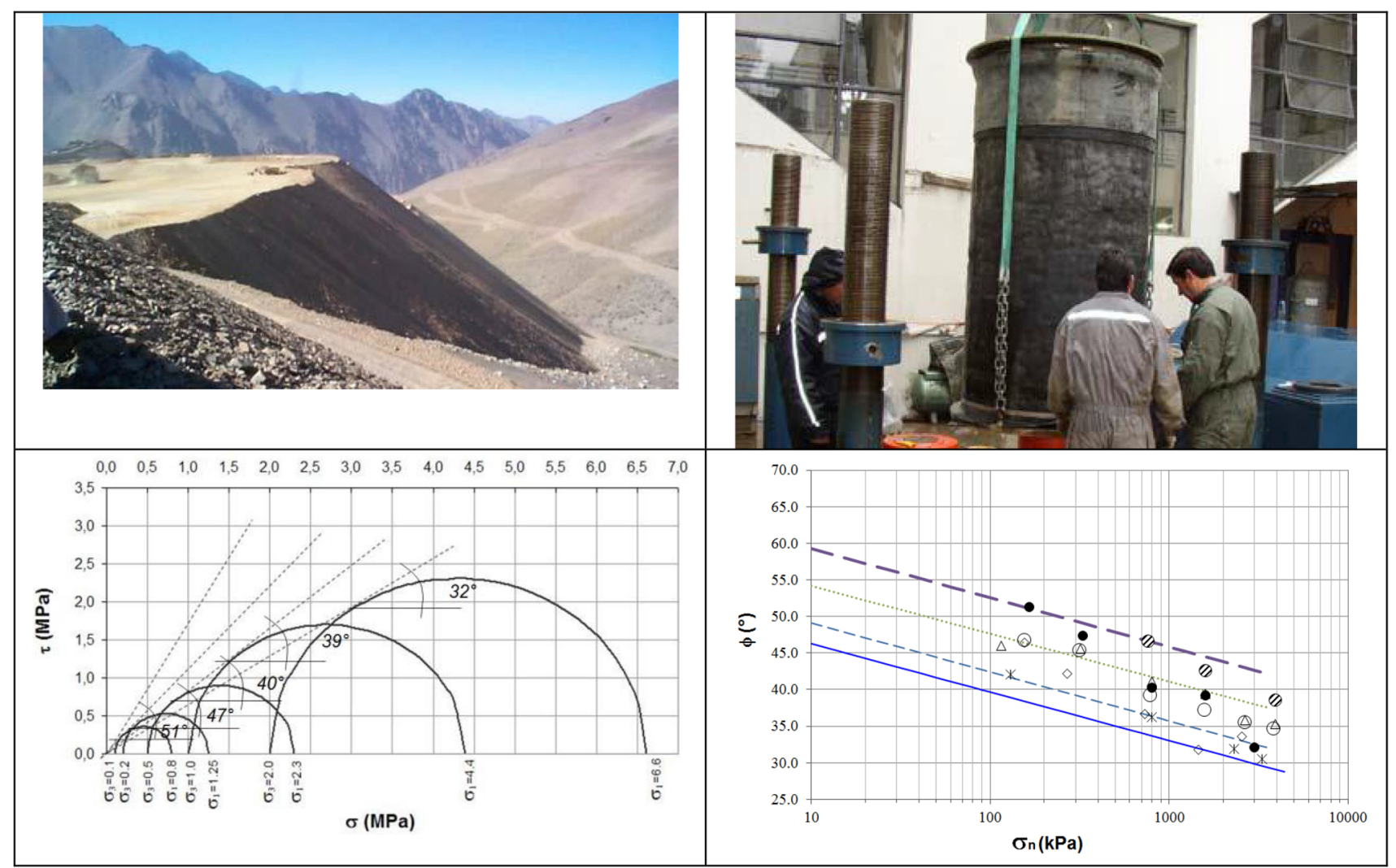

Fig. 16 In Chile, there are plans for mine-operations rock dumps with thicknesses far exceeding even the highest rockfill dams. A figure of $500 \mathrm{~m}$ has been seen. Consequently, some large-scale investigations of rockfill have been performed, one of which by SRK is reproduced with permission from Linero and Palma [17]. Note that Marsal [18] obtained comparable ranges of $\varphi_{\max }^{\prime}=46^{\circ}-53^{\circ}$, and $\varphi_{\min }^{\prime}=34^{\circ}-39^{\circ}$ from the lowest $\sigma_{3}^{\prime}$ of about 0.04 to $0.09 \mathrm{MPa}$ up to the highest $\sigma_{3}^{\prime}$ of about 2.4 to $2.5 \mathrm{MPa}$. There were some exceptions to this for the case of tests on mixtures of schist and (partly weathered) granitic gneiss for the Mica dam, with minimum values at the highest stress down to $28^{\circ}$, $29^{\circ}$ and $30^{\circ}$
TRIAXIAL TEST

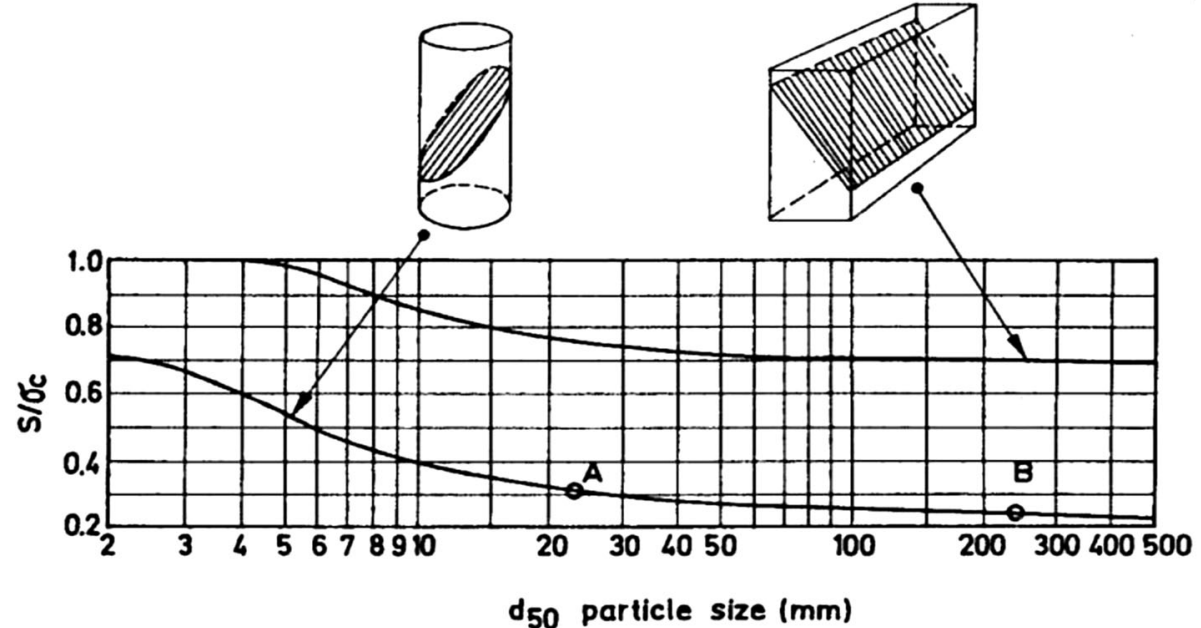

Fig. 17 An empirically developed way to estimate the approximate scale effect on particle strength $(S)$, based on the $d_{50}$ particle size. Note the differentiation of triaxial test data and the more realistic in- dam plane test data, which results in a few degrees higher frictional strength, as demonstrated in Table 2 
Table 2 In the same manner as JRC for rock joints, a given $R$ value, such as 6 in this example, causes the predicted frictional strength to change by $6^{\circ}$ for each decade change in effective normal stress, when using the proposed non-linear shear strength criterion

\begin{tabular}{llll}
\hline$\sigma_{n}^{\prime}$, in MPa (1) & Equivalent overburden (2) & $\phi^{\prime}$ plane (3) & $\phi^{\prime}$ triaxial (4) \\
\hline 0.0001 & $5 \mathrm{~mm}$ & $67^{\circ}$ & $65^{\circ}$ \\
0.001 & $50 \mathrm{~mm}$ & $61^{\circ}$ & $59^{\circ}$ \\
0.01 & $500 \mathrm{~mm}$ & $55^{\circ}$ & $53^{\circ}$ \\
0.1 & $5 \mathrm{~m}$ & $49^{\circ}$ & $47^{\circ}$ \\
1.0 & $50 \mathrm{~m}$ & $43^{\circ}$ & $41^{\circ}$ \\
10.0 & $500 \mathrm{~m}$ & $37^{\circ}$ & $35^{\circ}$ \\
\hline
\end{tabular}

Note $25.4 \mathrm{~mm}=1 \mathrm{in} ; 1 \mathrm{MPa}=145 \mathrm{psi}$

(This table was presented by Barton and Kjærnsli [13]). An exactly equivalent table was presented by Barton and Bandis [14] when presenting the effect of, e.g. 1000 times higher stress when progressing from a small-scale tilt test on a rock joint (Fig. 5), in which $\sigma_{n}^{\prime} \approx 0.001 \mathrm{MPa}$ at failure, to the much higher stresses $(\approx 1 \mathrm{MPa}) 40 \mathrm{~m}$ beneath a rock slope

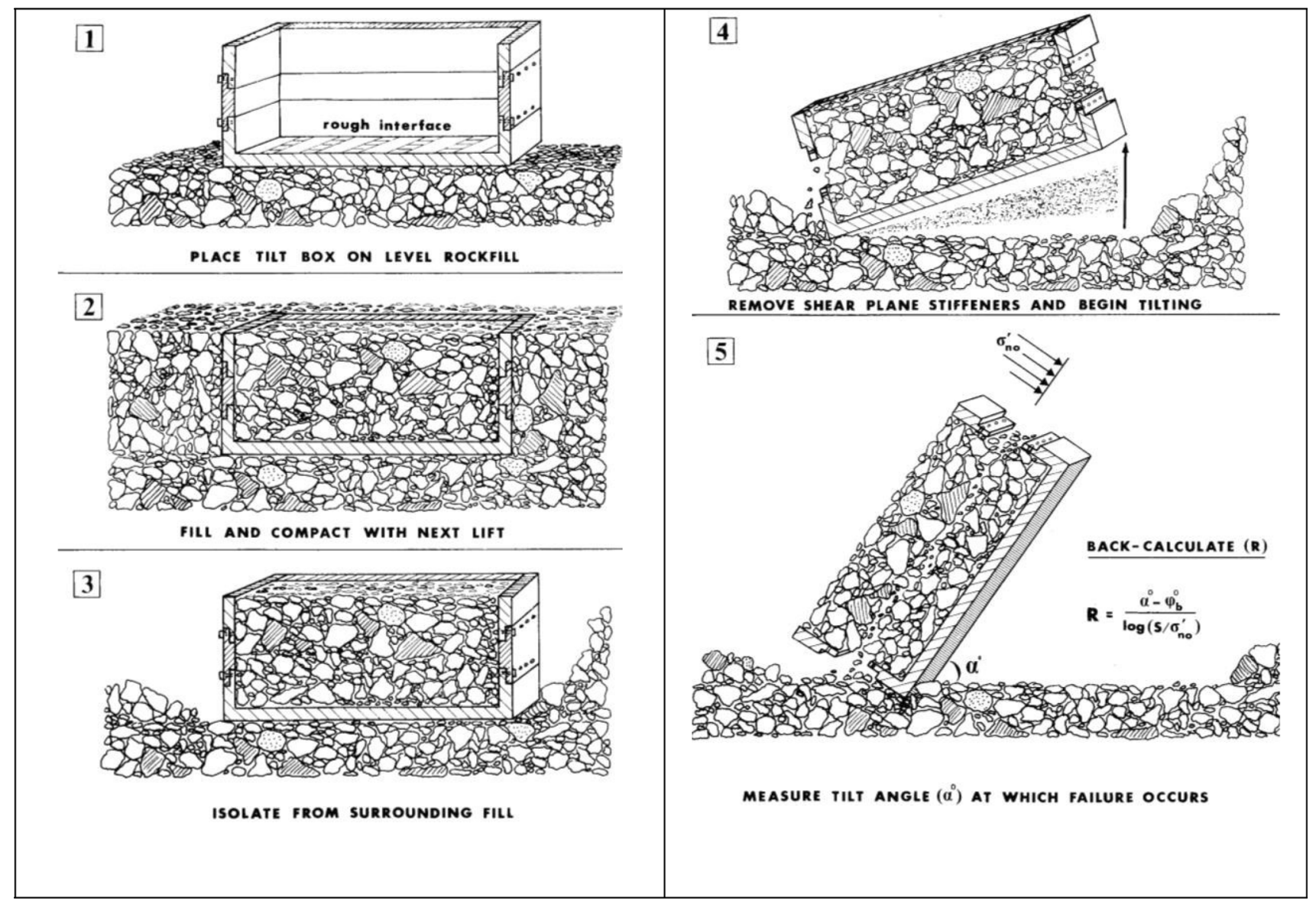

Fig. 18 Barton and Kjærnsli [13] suggested that full-scale tests could be made on rockfill, without needing to use parallel grading curves. The sequence of diagrams and accompanying texts by the writer were designed to be self-explanatory. Note that one 'error' discovered some years later when performing such tests at a dam site in Italy at

value shown in Fig. 6 (bottom-left diagram). The $\log _{10}$ (strength/stress) adjustment factor determines how many decades (or fractions of a decade) the change of stress 'multiplier' of $R$ (and JRC) will be.
$2 \times 2 \times 5 \mathrm{~m}$ scale (Fig. 19) was that the 'shear plane stiffener' which is to be moved before the test was too wide: material was lost from the outer parts of the shear plane during tilt testing, unless the gap was reduced to some $10 \mathrm{~cm}$

For example, a large-scale tilt test (as in Figs. 18, 19) with a normal stress at failure of about $0.01 \mathrm{MPa}$, using a rockfill material having a scaled compressive strength of $10 \mathrm{MPa}$ for the $d_{50}$ particle size, involves 


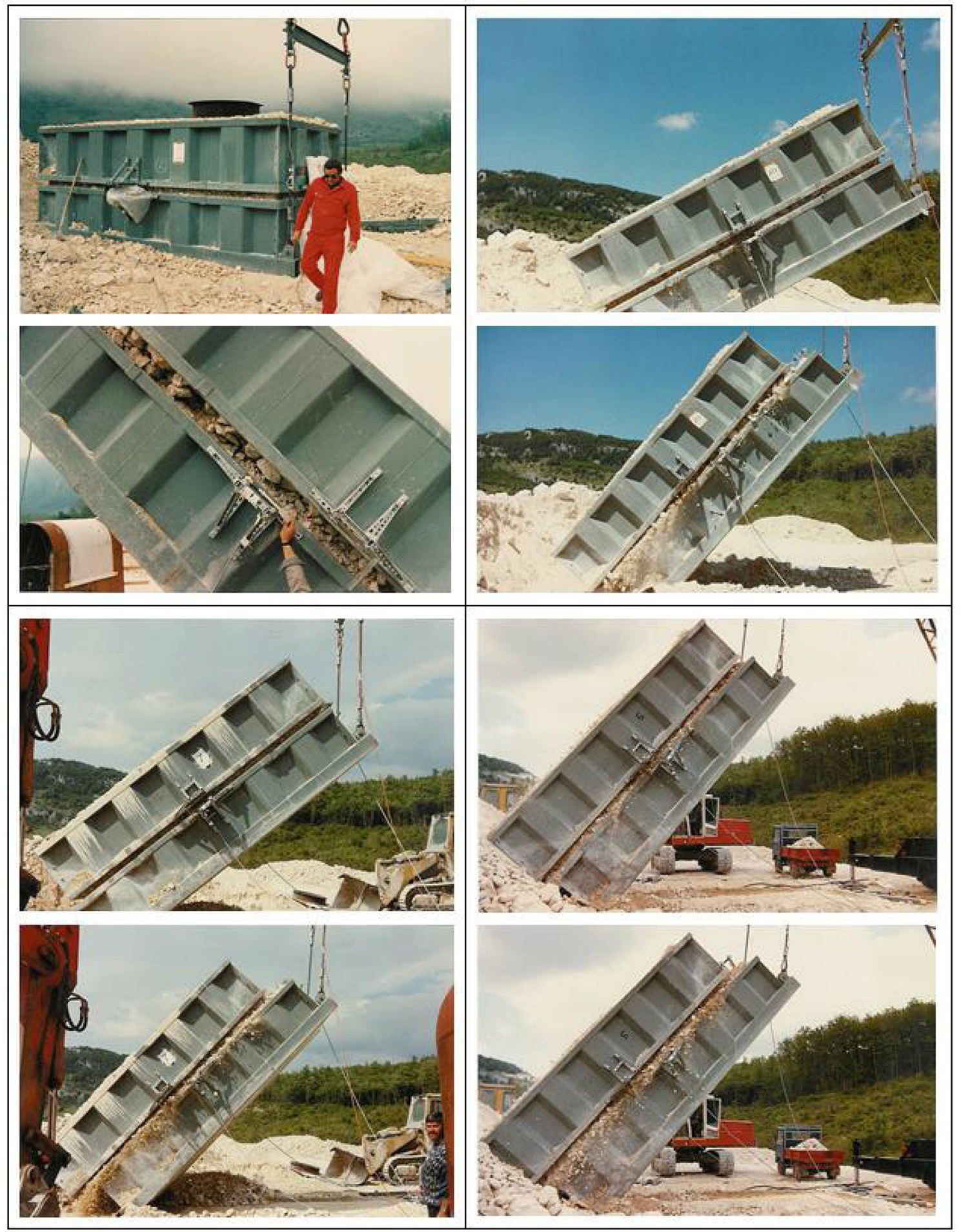

Fig. 19 Tilt testing of 'as-built' rockfill, as suggested in Barton and Kjærnsli [13], with performance of ten tests at a rockfill dam in Italy. The tilt-shear box measures $5 \mathrm{~m} \times 2 \mathrm{~m} \times 2 \mathrm{~m}$. Three tests are shown, using pairs of photographs. The top-left pair shows the

$\log _{10}(10 / 0.01)=3(\times R)$ for the case of the tilt test, while it will be $\log _{10}(10 / 1)=1(\times R)$ inside the dam at, e.g. $45 \mathrm{~m}$ depth. If we assumed $R=7$, there would, horizontal condition: a 10-15-cm gap is advised. The sheared 'detail' shows the displaced instrumentation (shear and dilation) in the postpeak (ultimate) condition. Note the relative absence of non-parallel shear (or 'toppling') due to uniform gravity loading

therefore, be a $14^{\circ}$ lower friction angle inside the dam than in the tilt test: for instance $48^{\circ}$ in the tilt test, reducing to $34^{\circ}$ inside the dam where the confining 


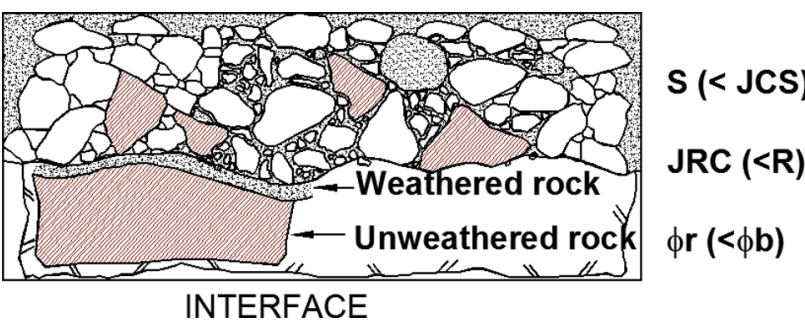

Fig. 20 The rockfill/rock-foundation interface problem includes the likelihood of a lightly weathered surface (even in glaciated terrain), so it is appropriate to suggest $\varphi_{\mathrm{r}}$ (implying $\varphi_{\mathrm{r}}<\varphi_{\mathrm{b}}$ and $r<R$ when using a Schmidt hammer in Fig. 10). The choice of JRC (meaning the interface is weakest) instead of $R$ (meaning that the interface is strongest) provides the test of whether shear failure may occur preferentially through the rockfill (or not at all) because of a strongly 'interlocked' foundation

stress is assumed to be $1 \mathrm{MPa}$, or 100 times higher than in the tilt test.

Figure 18 shows the Barton and Kjærnsli [13] suggestion for large-scale tests on dams under construction. By chance, NGI staff had arranged for such tests in Italy, just before the writer returned to NGI after 4 years in the USA in 1984. Due to pressing new administrative duties, the writer was not able to physically accompany the testing in Italy. The sequence of photographs later shown to the writer (some examples are given in Fig. 19) suggest that the Italian contractor at the dam did not follow the recommendation of 'standard compaction' within the 'next lift' of the dam, followed by 'excavation' of the tilt-shear box. Possibly they found this to be too burdensome. So it appears that other, probably less efficient methods may have been used to compact the rockfill before tilt testing. A bulldozer on a ramp is seen in one of the photographs. It appears that the tilt angles were mostly in the range of $45^{\circ}-$ $50^{\circ}$.
A particular feature of these large-scale tests is that the gravity loading provides a much more uniform loading than the usual top-platten-and-end-loading in a standard shear box. The relative absence of any tendency to rotate when tilted is easy to see. [In the case of some very rough rock joints, the top half of the tilt test sample needs to be made slender (low $H / L$ ratio) to prevent toppling (rotating) instead of parallel sliding. There seems to be no such problem with the 1/5 ratio seen in Fig. 19].

\section{From rockfill to interfaces}

Because some dam sites in glaciated mountainous countries like Norway, Switzerland, and Austria have insufficient foundation roughness to prevent preferential shearing along the rockfill/rock-foundation interface, artificial 'trenching' is needed. Various scales of investigation of interface strength have been published, and these were synthesized by Barton [6]. The physical reality of a rockfill/rock interface is illustrated in Fig. 20, and potentially correct input parameters for estimating the shear strength are suggested.

Figure 21 illustrates two rockfill dams with moraine cores, while they were under construction. Both appear to be on relatively smooth rock foundations, in particular the Norwegian example on the left. Here, it is uncertain if the foundation is rough enough to prevent the interface from being 'the weakest link'.

Figure 22 illustrates examples of these two categories of shearing, in which the 'weakest link' determines the mode of sliding: whether the interface is smooth enough and the particles big enough to prevent good interlock (JRC-controlled), or the opposite $R$-controlled behaviour, with preferential failure within the rockfill, due to good interlock across the interface. Numerous cases reported in the

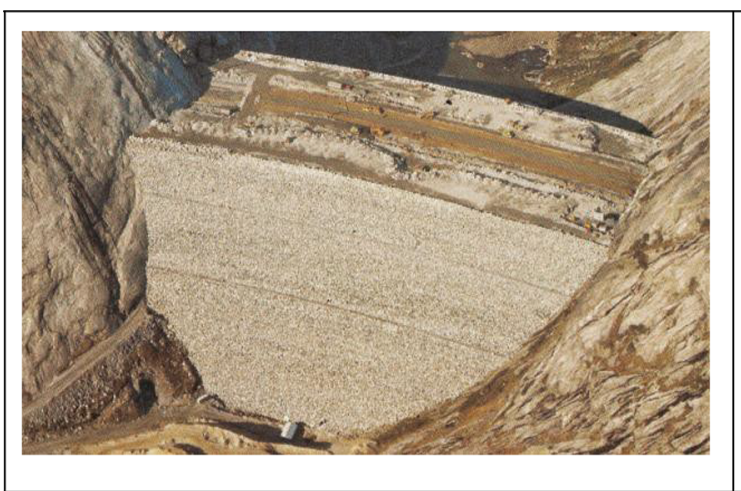

Fig. 21 Left The Svartevann dam in Norway appears to have limited roughness in parts of its steep (U-shaped valley) glaciated rockfoundation abutments. Right As will be demonstrated in Fig. 22, the

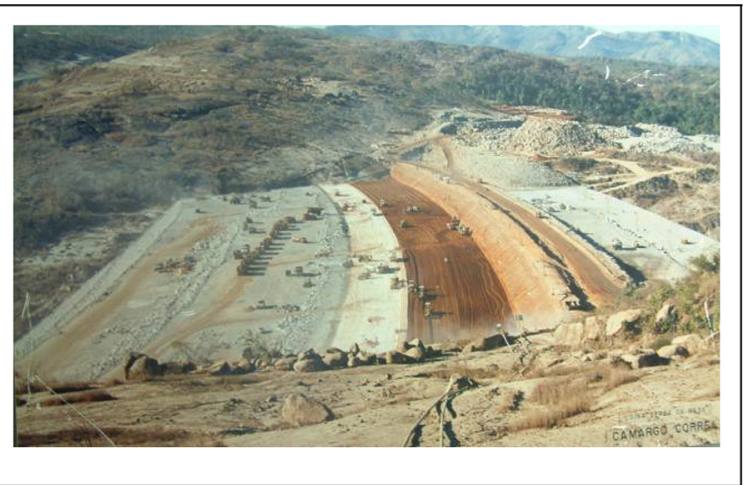

(discarded) boulders seen in the foreground of the Brazilian dam (Camargo Correa photo) are obviously too large to interlock with the relatively smooth rock foundation 


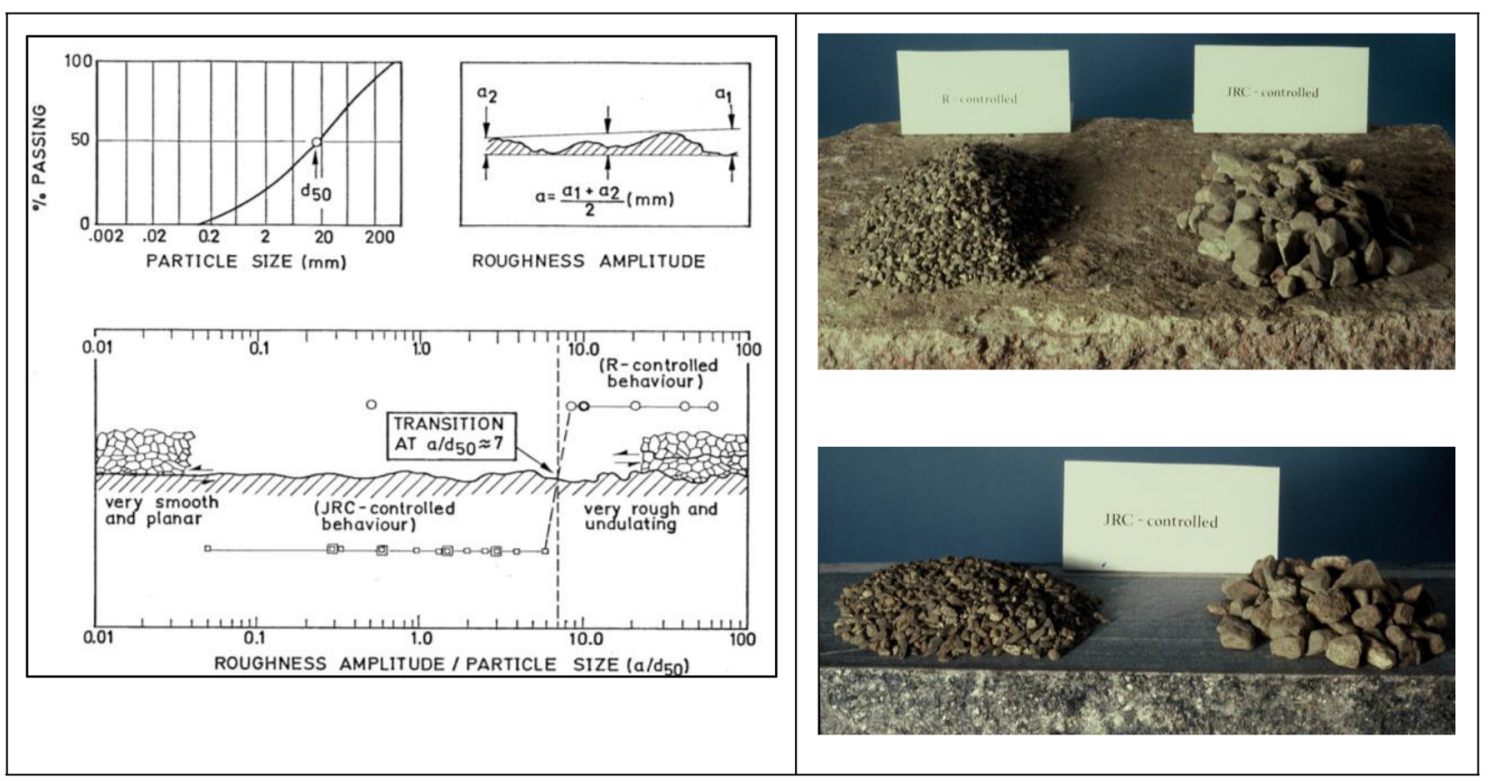

Fig. 22 Left The results of interface/rockfill and interface/sand (and gravel) direct shear tests can be separated by means of the ratio $a / d_{50}$, into $R$-controlled and JRC-controlled categories. The transition occurs

literature were analysed in unpublished research performed by the author, and can be summarized by the data points plotted in Fig. 22 (left). The $a / L$ versus $d_{50}$ ratios for the Norwegian dam shown in Fig. 21 are not known. However, JRC-controlled interface behaviour seems likely in places. The (discarded) boulders in the foreground of the Brazilian dam (right) would give JRC-controlled behaviour. They are too big to interlock with the smooth rock surface.

\section{Discussion}

This paper has seen an attempt to link the shear strengths of rockfill—with its many possible varieties, materials, porosities, stress levels - to the shear strength of rock and rock joints. Naturally, the key to such a linkage is the highly stressed points of contacts. Of course, in 1967, when the writer started experimenting with the shear strength of rough tension fractures, in an attempt to improve upon Mohr-Coulomb and Patton for describing rock joints, the full significance of the asperities in contact as seen in Fig. 4 (top-left) was not understood. Nevertheless, the first shear strength criterion involving the ratio of material compressive strength and effective normal stress was produced, and 10 years later, even for the case of weathered joints, this ratio continued to be a central part of the strength criterion, in the form JCS $/ \sigma_{n}$. For rockfill, we have found that $S / \sigma_{n}$, with both JCS and $S$ corrected for block size $\left(L_{n}\right)$ or particle size $\left(d_{50}\right)$, has strong relevance to the understanding of peak shear strength. at $a / d_{50} \approx 7$. Right Four examples of a/d $d_{50}$ which demonstrate either preference for interface sliding or preference for internal shearing in the rockfill. This can be verified (at low stress) by tilt testing

In remarkably painstaking work by Marsal [18], preoccupation with particle contacts and particle contact forces is reflected by the drawing of particle contacts in Fig. 23, and by an example of the statistics Raul Marsal produced, with observations of particle contacts numbering in their thousands.

The method used by Marsal to record the (undisturbed) number of contacts was novel in the extreme. He flooded the rockfill or gravel samples from the bottom upwards with paint, allowed it to dry for $24 \mathrm{~h}$, and then began the careful work of 'excavating' up to several thousand grains counting the paint-coated contacts as he progressed. This deserves our strong admiration.

Of course, Marsal was characteristically modest in his conclusions about work remaining to be done. Presumably, due to capillary effects, the paint-covered contacts, while an accurate reflection of numbers, must have presented a remaining question about actual areas in contact and, therefore, actual stress levels. In work on rock joints, the writer has assumed that the small percentage of asperities in contact must raise actual stress levels up to UCS or JCS levels. Whether this could hold for rockfill is less certain, as too much particle adjustment is possible.

\section{Conclusions}

1. Rock material, which inevitably controls the behaviour of rock joints and the particulate components of rockfill, plays an extra sensitive role in shear strength 


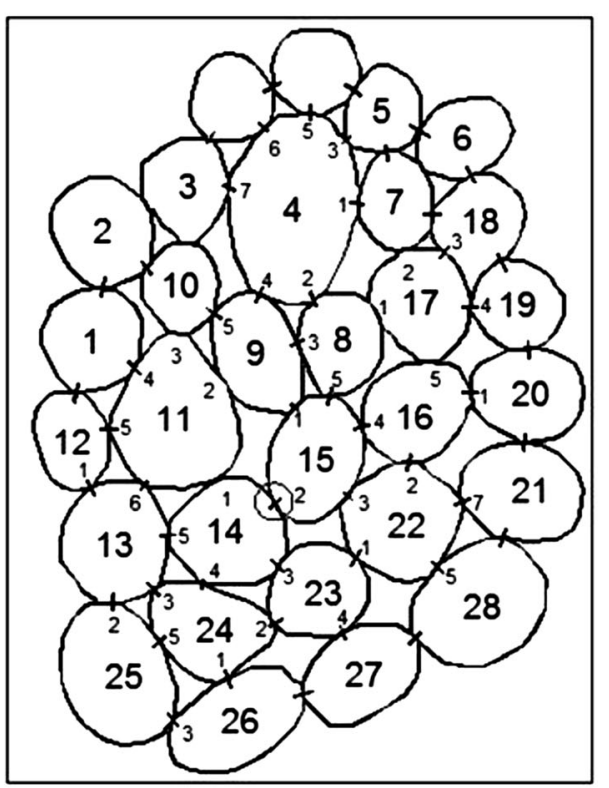

Fig. 23 A brief example of the painstaking work performed by Marsal [18] on the subject of particle contacts and their possible stress levels. The numbered contacts shown here are referenced to a horizontal plane, and the statistics on the right refer to a loose,

development, because the true contact areas transferring the shear and normal stresses are very small, and therefore, the stress levels are correspondingly very high. So the crushing strength of the rock becomes important.

2. The asperities in contact on either side of a rock joint and the small contacting points around the rockfill particles appear to follow the same basic non-linear relation between shear strength and effective normal stress. Both materials dilate strongly at low stress, causing high apparent total friction angles. At high stress levels there is reduced dilation and asperity strength is mobilized due to crushing.

3. It is now known that when the local confining pressure reaches approximately the level of the uniaxial compressive strength, the rock in question will generally have reached its maximum possible strength, or 'critical state'. This is important at these points in contact.

4. The strong non-linearity and lack of actual cohesion for both rock joints and rockfill give a special bonus. One can perform extremely low-stress gravity-loaded tilt tests in both cases, using the non-linear strength criteria to extrapolate results to many orders of magnitude higher stress.

5. Raúl Marsal played a strong indirect role in linking rockfill and rock joint behaviour because of his painstaking investigations of the particles-in-contact phenomena, and his presentation of triaxial test results in a format familiar in rock mechanics, namely $\tau$
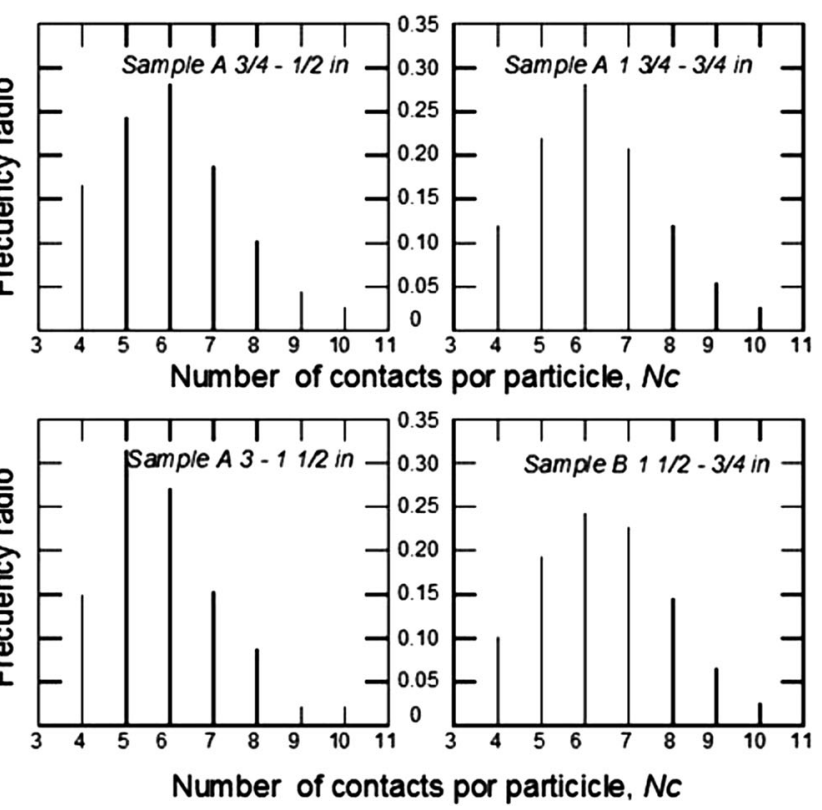

uniformly graded gravel. In this case, the number of contacts $N_{\mathrm{c}}$ ranged from 4 to 10 per particle, with means between 5.9 and 6.4. In the case of densely packed specimens, the range was $4-13$, with means ranging from 7.1 to 8.3

versus $\sigma_{n}^{\prime}$, as a result of analysing the triaxial strengths in relation to the failure planes.

6. This paper has mostly addressed only the peak shear strengths of rock joints and rockfill. The mobilization of friction and dilation up to peak strength, followed by degradation of roughness towards ultimate and residual strength is also important if numerical modelling is to be performed. The appendix shows by means of three figures how this can be estimated for the case of rock joints.

Open Access This article is distributed under the terms of the Creative Commons Attribution 4.0 International License (http://crea tivecommons.org/licenses/by/4.0/), which permits unrestricted use, distribution, and reproduction in any medium, provided you give appropriate credit to the original author(s) and the source, provide a link to the Creative Commons license, and indicate if changes were made.

\section{Appendix}

Peak strengths have been the subject of this paper. In case the shear strength-displacement is required, for instance as input to distinct element modelling such as UDEC or PFC, then the $\mathrm{JRC}_{\text {mobilized }}$ concept can be used (for the case of rock joints). The matching of Bandis experiments with Barton predictions is shown [8]. There seems no reason why ' $R_{\text {mobilized' }}$ could not be used for rockfill. 

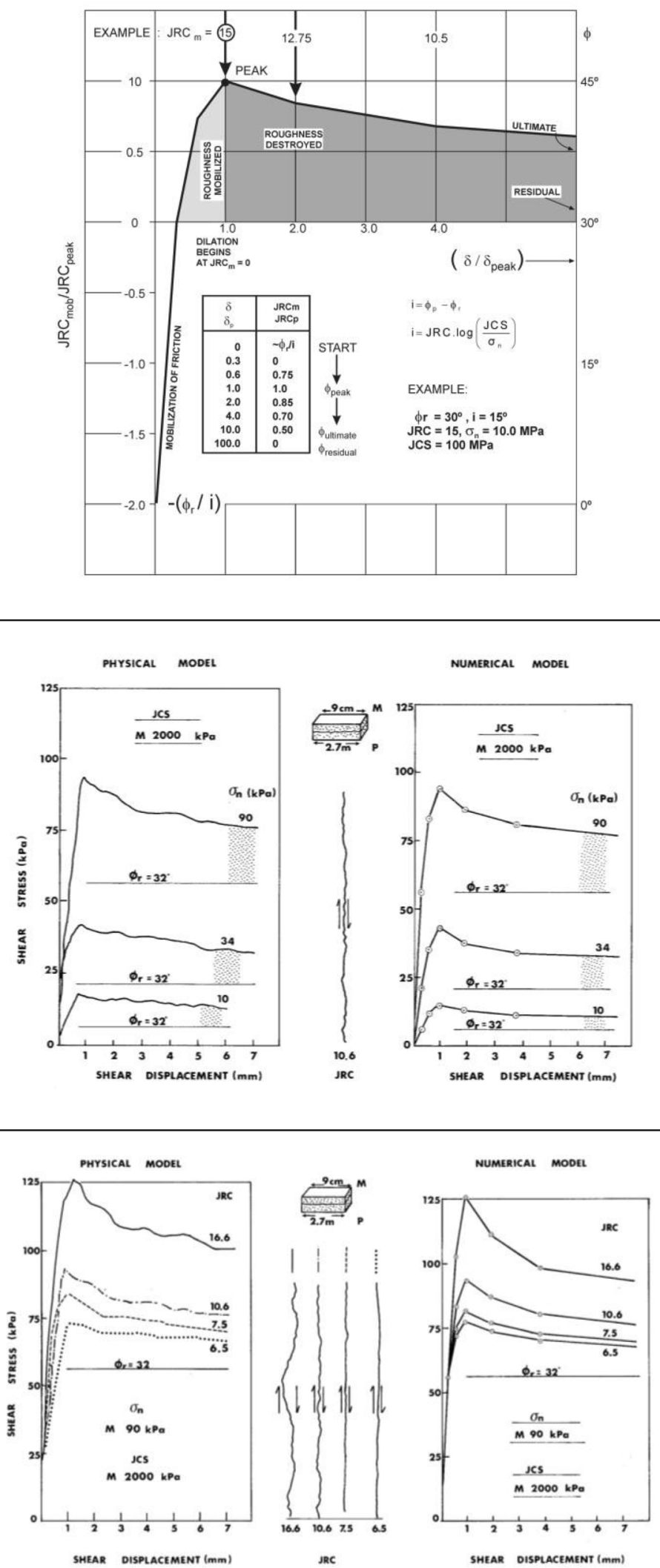


\section{References}

1. Bandis S (1980) Experimental studies of scale effects on shear strength and deformation of rock joints. Ph.D. Thesis, Univ. of Leeds, England.

2. Bandis S, Lumsden A, Barton N (1981) Experimental studies of scale effects on the shear behaviour of rock joints. Int J Rock Mech Min Sci Geomech Abstr 18:1-21.

3. Barton N (1971) A model study of the behaviour of steep excavated rock slopes. Ph.D. Thesis, Univ. of London.

4. Barton N (1973) Review of a new shear strength criterion for rock joints. Eng Geol (Elsevier, Amsterdam) 7:287-332 (Also NGI Publ. 105, 1974).

5. Barton N (1976) The shear strength of rock and rock joints. Int J Rock Mech Min Sci Geomech Abstr 13(9):255-279 (Also NGI Publ. 119, 1978).

6. Barton N (1980) Evaluation of shear strength in rockfill and between rockfills and rock foundations. NGI report 53101-2:67 (in Norwegian).

7. Barton N (1981) Shear strength investigations for surface mining. In: 3rd international conference on stability in surface mining, Vancouver, Ch 7. AIME, pp 171-192.

8. Barton N (1982) Modelling rock joint behaviour from in situ block tests: implications for nuclear waste repository design. Office of Nuclear Waste Isolation, Columbus, OH, p 96, ONWI308, September 1982.

9. Barton N (1993) Physical and discrete element models of excavation and failure in jointed rock. In: Keynote lecture presented at ISRM international symposium on assessment and prevention of failure phenomena in rock engineering, 5-7 April, Istanbul, Turkey.

10. Barton N (1999) General report concerning some 20th century lessons and 21st century challenges in applied rock mechanics, safety and control of the environment. In: Proceedings of 9th ISRM congress, Paris, vol 3, pp 1659-1679, Balkema, Netherlands.
11. Barton N (2006) Rock quality, seismic velocity, attenuation and anisotropy. Taylor \& Francis, UK \& Netherlands, p 729.

12. Barton N, Choubey V (1977) The shear strength of rock joints in theory and practice. Rock Mech 10(1-2):1-54 (Vienna: Springer. Also NGI Publ. 119, 1978).

13. Barton N, Kjærnsli B (1981) Shear strength of rockfill. J Geotech Eng Div Proc ASCE 107(GT7):873-891 (Proc. Paper 16374, July).

14. Barton N, Bandis SC (1990) Review of predictive capabilities of JRC-JCS model in engineering practice. In: Proceedings of International Symposium on Rock Joints. Loen 1990, pp 603-610.

15. Becker E (1972) Strength and deformation characteristics of rockfill materials under plane strain conditions. Ph.D. Thesis, Univ. of California, Berkeley.

16. Leps TM (1970) Review of the shearing strength of rockfill. J Soil Mech Found Div ASCE 96(SM4):1159-1170 (Proc. Paper 7394, July 1970).

17. Linero S, Palma C (2006) Caracterización geotecnica de materiales estériles para diseño de depósitos mineros de gran altura (Geotechnical characterization of rock materials for design of high rock dumps). In: Proceedings of 6th South American Rock Mechanics Congress, Cartagena, Colombia.

18. Marsal RJ (1973) Mechanical properties of rockfill. In: Hirschfeld RC, Poulos SJ (eds) Embankment-dam engineering, Casagrande volume. Wiley, New York, pp 109-200.

19. Marachi ND, Chan CK, Seed HB, Duncan JM (1969) Strength and deformation characteristics of rockfill materials. Dept. of Civ. Eng., Univ. of California, Berkeley, p 139.

20. Patton FD (1966) Multiple modes of shear failure in rock. In: Proceedings of 1st ISRM Congress, Lisbon, vol 1, pp 509-513.

21. Singh M, Raj A, Singh B (2011) Modified Mohr-Coulomb criterion for non-linear triaxial and polyaxial strength of intact rocks. Int J Rock Mech Mining Sci 48(4):546-555. 